\title{
Puentes de probable cronología califal o taifa, en Bocairent (La Vall d'Albaida, Valencia)
}

\author{
Agustí Ribera* \\ Joaquim Bolufer*** \\ Josep Pascual* \\ J. D. Boronat*.
}

\begin{abstract}
RESUMEN
Se trata de dar a conocer la existencia de tres pequeños puentes ubicados en las inmediaciones de Bocairent, comarca de la Vall d'Albaida (Valencia), presentando un avance de su estudio, con descripción y primeras planimetrías.

Estos puentes se encuentran en viales muy secundarios en la actualidad, e incluso fuera de uso en un caso. Realizados en canteria, con sillares de piedra local, su antigüedad es indudable. A falta de otros datos, por el contexto y por sus propias características edilicias, se plantea la hipótesis de que fueran construidos hacia finales del siglo X, o principios del siglo Xl. Su construcción estaría relacionada con la adecuación de los accesos al hisn de Bocairent y, probablemente, con el paso de un camino entre la costa -Deniay el interior peninsular.
\end{abstract}

PALABRAS CLAVE: Arqueologia medieval. Puentes. Bocairent. Caminos. Denia. Xarq al-Andalus.

\begin{abstract}
The intention of this article is to give knowledge about the existence of three small bridges near the village of Bocairent in the Vall d' Albaida district of Valencia and to present primary studies and plans of them. These bridges are situated on what are these days classed as only very secondary routes and, indeed, one of them is actually out of use.

Constructed in masonry with ashlar hewn from local stone their antiquity is beyond doubt. By assessment of context and features and without more detailed information, we have come to assume that they were built sometime towards the end of the $X$ century and beginning of the $\mathrm{XI}$. It is believed that these bridges were built to ease access to Bocairent "hisn" and are probably also related to an old way whose path extends inland from the coast at Denia.
\end{abstract}

KEY WORDS: Medieval archaeology. Bridges. Bocairent. Pathways. Denia. Xarq al-Andalus.

\section{INTRODUCCIÓN}

Durante las campañas de prospección arqueológica en el alto Clariano ', centradas en los grupos de cuevas artificiales denominadas graneros de acantilado (coves finestra en cingle, greniers

de falaise etc.), (RIBERA Y BOLUFER, 1994), de época medieval andalusí, tuvimos ocasión de realizar trabajos de campo encaminados a obtener información sobre el poblamiento y otros aspectos directamente relacionados, entre ellos las hipotéticas vías de comunicación. Fruto de

*Museu Arqueològic d'Ontinyent i la Vall d'Albaida. Plaça Major - I. 46870 Ontinyent. Valencia.

**Museu Arqueològic i Etnogràfic Soler Blasco de Xàbia. Primícies - I. 46870 Xàbia. Alicante.

I Campañas llevadas a cabo por nosotros entre 1994 y 1998, autorizadas y subvencionadas por la Direcció General del Patrimoni Artístic, de la Conselleria de Cultura, de la Generalitat Valenciana, y interrumpidas desde dicho año de 1998. El área objeto de las prospecciones - Capçalera del riu d'Ontinyent, o alto Clariano-, comprende parte de los términos municipales de Bocairent, Ontinyent i Alfafara, confluyendo las comarcas de la Vall d'Albaida i el Comtat, a caballo de las actuales provincias de Valencia y Alicante. 
estos trabajos fue la localización y estudio preliminar de los tres pequeños puentes que ahora se presentan ${ }^{2}$.

Los puentes se ubican en el término municipal de Bocairent, localidad de la Vall d'Albai$\mathrm{da}$, comarca de interior y a unos $90 \mathrm{Km}$ al sur de Valencia.

Tratándose de puentes pequeños, o de segundo orden en comparación, por ejemplo. con el gran puente bajo-medieval de Bocairent o con otros posteriores de la zona, han pasado desapercibidos en las obras generales sobre puentes antiguos valencianos; véase por ejemplo el trabajo de C. Sanchis (SANCHIS DEUSA, 1994).

Situados en las proximidades del núcleo urbano de Bocairent, los puentes a los que nos referimos salvan los barrancos de la Frontera, Perinos y Canyaret (Fig. 2). Las primeras referencias que conocimos sobre alguno de estos puentes se deben a D. Francisco Vañó Silvestre (VAÑÓ, 1988), Cronista Oficial de Bocairent, quien los califica, junto a otros claramente bajo-medievales, como de época romana o tardo-romana. Sin ofrecer mayores precisiones técnicas ni documentación gráfica y aún con divagaciones un tanto peculiares, éste artículo resulta de especial interés por las numerosas informaciones de carácter local que aporta.

Desde el primer momento constatamos la singularidad y el gran interés de estos puentes, y decidimos tratar de acometer su estudio detallado. Durante las campañas de prospección citadas, intermitentemente, se realizaron los trabajos de limpieza, medición, documentación fotográfica y planimétrica, que en parte ahora se muestran. No obstante, no fue hasta 1998 cuando localizamos un tercer puente, mucho peor conservado, en el que los trabajos fueron muy parciales.

Cabe decir que han de considerarse trabajos preliminares, puesto que para obtener su visión completa, para su más correcta apreciación, estudio y puesta en valor, serían precisos nuevos trabajos de limpieza, excavación y desenterramiento, ya que en ningun caso se ha constatado el terreno firme donde se asientan, encontrándose muy cegados o colmatados de sedimentos. Obviamente estas labores, que esperamos emprender en breve, deberían insertarse dentro de un proyecto arquitectónicopatrimonial global que, con los fondos necesarios, incluyera al menos su consolidación y adecuada restauración, de manera inmediata a su desenterramiento, amén de otras medidas preventivas, que garanticen su preservación; motivos principales, entre otros, por los que, dada su complejidad ${ }^{3}$, se ha ido demorando nuestra actuación sobre ellos.

\section{DESCRIPCIÓN DE LOS PUENTES}

\section{PUENTE I: \\ Puente sobre el barranco de la Frontera}

El puente sobre el barranco de la Frontera, también llamado del Maset Giner, del camí vell de Banyeres ${ }^{4}$, es una magnífica construc-

2 Escuetos avances de resultados y noticias de los trabajos se fueron dando a Conselleria en las diferentes Memorias preliminares de las campañas de prospección, así como en los resúmenes de actuaciones anuales del museo (MAOVA). Un extracto de estas notas, en catalán, ha sido remitido a una revista local de Bocairent (RIBERA; PASCUAL, en prensa).

3 En los tres puentes se habría de estudiar la construcción de pequeños diques aguas arriba, para contener y registrar los aportes sedimentarios. En el puente de la Frontera, aunque se sitúa en un camino poco transitado, se habría de cerrar totalmente el tránsito motorizado. Idem en el puente de Perinos, pero en este caso se habría de habilitar una vía alternativa y desembarazar el tramo actual de tubos de hormigón. En el de Canyaret se habría de proceder a una correcta impermeabilización de la acequia, e incluso desviarla, etc. Consideramos que todas esta variables -así como la consolidación y restauración- han de estar proyectadas y presupuestadas antes de lanzarse al desaterramiento de los puentes.

4 Podría ser el llamado en el s. XVI Pont de Micalàs (VILLARRUBIA; SATORRES, 1989), por la situación, cercana a esta finca, pero no está claro, pues también podría referirse a otro puente que existe inmediato a la finca, pero por otro camino, el que viene del mas de la Frontera; bien es cierto que este otro puente no parece tan viejo, sino del s. XVII como mucho. 
ción de cantería realizada en sillares de piedra local ${ }^{5}$. Presenta la particularidad de haberse construido en dos fases, una primera más antigua, que creemos de época andalusí, califal o taifal, y que es la más relevante, a la que se le adosó otro cuerpo, en época bajo-medieval, en la parte oeste. Aunque medirá más de 15 $\mathrm{m}$ de largo total, la obra de sillares propiamente dicha, incluida la bóveda y los estribos alcanza unos $10 \mathrm{~m}$ de largo. La altura total no es reconocible sino hasta la línea de imposta, debido a los sedimentos acumulados. Teniendo en cuenta que la flecha es de 2,20 m, la altura total original desde la base de la obra hasta la parte inferior de la clave debe ser de unos $4,5 \mathrm{~m}$, a los que hay que añadir los 0,7 $\mathrm{m}$ de la clave, más otros $2 \mathrm{~m}$ de obra de mampostería común que se superpone, hasta llegar a la suela o calzada actual; por tanto la altura total debe ser de poco más de $7 \mathrm{~m}$, de los cuales los 2,5 m inferiores no son visibles, ya que se encuentran soterrados. La anchura total es de 4,75 m de los cuales, los 2,60 de levante corresponden a la obra primitiva. La anchura de la suela es menor debido a que la obra de mampostería común, por encima del extradós, está levemente ataludada, lo que denota que no debe ser original. La luz mide 4,40 m. El arco formero de la bóveda es cercano al medio punto aunque se encuentra deformado por el desgaste, rotura y desplazamiento de las dovelas. Éstas son largas y estrechas, de unos 0,2-0,3 $\times 0,6-0,7 \times 0,4 \mathrm{~m}$. La clave se encuentra diferenciada al ser una pieza mayor y tener el doble de grosor. El aparejo es de muy buena factura, con los sillares bien escuadrados, de medidas próximas a los $0,7 \times 0,4 \times 0,2 \mathrm{~m}$. Mientras que en lo que se puede ver de las partes inferiores de los estribos, los bloques están dispuestos a soga, o de plano, a juntas encontradas por tercios, en las partes altas presenta aparejo seudo-diatónico, alternándose las piezas dispuestas de largo con los tizones, o piezas dispuestas de través. En algunos puntos se observan dos o tres tizones juntos, a la manera de sardinel, como es frecuente en la arquitectura andalusí de época califal. La imposta, muy bien remarcada por una línea de sillares que sobresale unos 0, I0 m, se sitúa por debajo de la línea de inicio del arco y vuela por ambos lados del intradós. Por encima de ella hay 5 mechinales en cada lado, para apoyar la cimbra en el momento de su construcción. El paramento externo presenta un rebaje vertical de galces rectos que remarca la parte principal del puente, con el arco y parte de los estribos retranqueados unos 0,16 m como es común en muchas puertas arqueadas andalusíes.

La ampliación hacia poniente de época bajomedieval (entre finales del siglo $X V$ y principios del XVII aproximadamente), consiguió casi duplicar la amplitud del puente -2,15 m más- manteniendo los trazos generales de la obra anterior; no sólo la bóveda, sino incluso la imposta se continúa en el mismo nivel y con idénticas proporciones. Aun así, no presenta mechinales y la obra de cantería se limita a la bóveda, siendo los riñones de mampostería ordinaria.

Por suerte, el hecho de que se adosara esta obra en la parte de aguas arriba, la reforzó en su día y habrá contribuido al mantenimiento de la construcción antigua hasta hoy.

\section{PUENTE 2:}

\section{Puente sobre el barranco de Perinos}

El puente sobre el barranco de Perinos, también llamado pont de l'Alboret, pont de l'Abeurador, es una bella obra de cantería realizada en sillares de piedra calcárea local. Sus dimensiones generales son: un mínimo de $6 \mathrm{~m}$ de largo, unos $6 \mathrm{~m}$ de altura -aunque la sedimentación cubre unos 2,5 m- mientras que su anchura originaria era de unos 2,80 m; Con posterioridad se le fueron añadiendo tramos -ace-

5 Se trata de una caliza arenosa que, aunque no se han hecho análisis, debe proceder de unos afloramientos existentes unos 200 m al nordeste del puente, en las inmediaciones del mas de Pastetes, por donde discurre el camino y en donde se observan señales de extracciones, recortes en la roca así como algunas carriladas que debemos suponer corresponden al paso del cami vell de Banyeres, en época bajo-medieval -ampliación del puente-, según se verá mas adelante. 
quia adosada, tubos de hormigón...-, siempre al lado de aguas abajo -NE- hasta llegar a los más de $6 \mathrm{~m}$ actuales de suela. Su luz es de 3 $\mathrm{m}$. El arco formero de la bóveda se aproxima al medio punto, aunque se encuentra deformado por el desgaste o desplazamiento de algunas dovelas. Estas tienen unas medidas medias aproximadas de 0,6 6 0,5 $\times 0,3$ aunque las medidas de los bloques son muy diversas. La clave, aunque identificable, no está resaltada. En general, el aparejo es de buena factura, combinándose en ambos estribos, los sillares puestos de plano con los dispuestos de canto, y en algunos casos mostrando varios tizones juntos. También hay algún sillar almohadillado, o dejado de labrar en su cara visible, como solía hacerse-aunque no exclusivamente- en época romana. Tiene una imposta muy bien resaltada, situada por debajo de la línea de inicio del arco y que corre a lo largo de ambos lados del intradós. Por encima de ella se ven, en cada uno de los laterales, los mechinales -en número de 4- hechos para soportar la cimbra. Los riñones son de cantería, pero no así la parte superior, que es de mampostería común bastante floja, quizás por haberse perdido la obra original. En el riñón izquierdo (SW) aun se conserva una pequeña canal de desagüe original, realizada en piedra. Simétricamente, en la cara exterior de ambos estribos, en la pared, existe un resalte vertical, de galce recto, de manera que el espacio central, con el arco y parte de los estribos, queda retranqueado o rebajado en su paramento, como ocurre en algunas construcciones andalusíes, especialmente puertas, donde en ocasiones este retranqueamiento se completa por la parte superior formando un alfiz. Al igual que en el puente anterior, el hecho de habérsele adosado otras construcciones -en este caso en la parte de aguas abajo- habrá contribuido al mantenimiento de la construcción.

\section{PUENTE 3: \\ Puente sobre el barranco de Canyaret}

El puente sobre el barranco de Canyaret, conocido también como pont de la Noguereta, el Pas de l'Aigua ${ }^{6}$, es una antigua construcción de cantería, de características semejantes en todo a las otras dos ya descritas. De los tres puentes, el de Canyaret es el peor conservado, ya que parece haber perdido buena parte de las caras externas, incluso parte de la bóveda, donde se observa claramente una refacción, perdiendo amplitud; se encuentra muy afectado por la erosión y cubierto por concreciones calcáreas, originadas por las fugas de agua de la acequia superpuesta.

Por lo poco que se puede observar de su factura, en el estado en que se encuentra -sería preciso realizar una buena limpieza de vegetación y una cuidadosa extracción de las concreciones-, debe ser muy parecido al del barranco de la Frontera, ya que las dimensiones tanto de luz -aproximadamente 4,40 m,- como de amplitud -2,60 m- son coincidentes con aquella construcción. En las partes mejor conservadas, básicamente los estribos y sectores bajos del intradós, los bloques o sillares y su disposición son muy similares al de la Frontera.

Igualmente presenta una imposta volada en ambos lados del intradós, ésta más gruesa o de mayor altura que en los casos anteriores -25 cm-, por encima de la cual solamente se llega a ver uno de los al menos 5 mechinales que debe tener, ocultos bajo de la capa de concreciones calcáreas. También presenta rebaje o leve retranqueo vertical del paramento -15 $\mathrm{cm}$ - en la parte central de la construcción, al menos en el lado sur. El largo total de la obra original de cantería, incluyendo estribos y arco, debería aproximarse a los $8 \mathrm{~m}$.

6 El barranco recibe también el nombre de l'Horta. Aparece un pont de la Noguera en unos afrontaments del año I5।8, que se acomoda bien con la situación de este puente, ya que se encuentra in orta dicte ville... y afronta ...cum via qua tenditur al molí de la Font. -Arxiu Municipal d'Ontinyent, Fons notarial, Sign. N-I5, Pere Calatayud-. (Agradecemos al archivero de Ontinyent don Vicent Terol, el habernos facilitado estos datos así como otras búsquedas infructuosas en esta dirección). En I5I7 también aparece un pont de na Gueralda, que a pesar de que afronta cum via qua tenditur a sent Jaume, no hemos sabido localizar -como no sea un precedente del actual pontón de la foia d'en Palau, la obra vieja del cual podría ser del s. XVII. Por lo que parece, estos dos puentes, que deberían estar cercanos, siguen apareciendo en la documentación al menos un siglo más tarde -s. XVII-, momento en que también aparece la partida de la foia d'en Palau (VILLARRUBIA; SATORRES, 1989), lo que contradiría, por duplicidad, la ubicación que hemos indicado para este pont de na Gueralda. 
El cambio de funcionalidad, de vial a acueducto - con senda adjunta-, debe ser secular; debería producirse al menos ya en época bajomedieval, momento en que el camino al cual servía ya estaba inutilizado -en la actualidad todos los alrededores son campos, sin que pase ningún camino-. Por su cota y proximidad, el antiguo camino debería venir desde el puente del barranco de Perinos (a I,4 km al este) siguiendo la curva de nivel de 620/630m, aproximadamente.

\section{CONSIDERACIONES CRONO- CULTURALES Y ESPACIALES}

En el apartado descriptivo anterior ya se habrá advertido nuestra convicción en datar en época medieval andalusí, y concretamente en los momentos avanzados o finales del califato omeya, la construcción de estos puentes, en detrimento de la otra única opción posible y, en principio, también factible: la época romana. Cabe quizás explicar que este convencimiento lo tenemos desde el primer momento, en parte debido al conocimiento previo de muchas otras obras, bien datadas, de la arquitectura de esta época Omeya, desde Gormaz ${ }^{7}$ (ZOZAYA, 1988; 200I) a Madinat al-Zahra (TORRES BALBÁS, 1987; LÓPEZ CUERVO, 1985; ACIÉN, 1987; VALLEJO, 1995; 200 I), y pasando por muchas otras aisladas, menores -y no tan menores- extendidas por la geografía peninsular, y entre ellas también algunos puentes - puente de Guadalajara (TORRES BALBÁS, 198I, 1987; PAVÓN MALDONADO, 1990; 1999), puentes y acueductos de los alrededores de Córdoba. (TORRES BALBÁS, 1987; PAVÓN MALDONADO, 1990; ARJONA CASTRO, 1999) etc. Bien es cierto que esta arquitectura de época califal, que podríamos definir como "de calidad", realizada en cantería, es realmente rara en el país Valenciano, o en Xarq al-Andalus en general, donde hasta el momento se conocen muy pocas obras.

De hecho solamente muestras muy reducidas, fragmentarias o parciales se pueden ver por ejemplo en la Rápita de Guardamar ${ }^{8}$ o en otras de Valencia ciudad ${ }^{9}$. Menos significativas todavía son otras citadas por algunos autores, como pueden ser las de Ifac, Rafal o Montroi ${ }^{10}$, entre otras muchas posibles, que además deben ser posteriores. También están datadas posteriormente los restos de la puerta de la Torre del Mig, y otras de la alcazaba de Denia, hechas en sillería (AZUAR, 1989b). Quedaría por tanto, y como magnífica excepción, el castillo de Alpont "'.

Esta escasez, junto a la dificultad de distinguir a menudo las obras de esta época (siempre y cuando no utilicen arco de herradura) de las propiamente romanas -igualmente escasas en el País Valenciano-, debido a que, como es sabido, las técnicas constructivas de cantería de época andalusí se basan mayormente en las obras clásicas, sobre todo de tradición romana -que conforma un substrato formal común extendido a todas las zonas mediterráneas ${ }^{12}$, incluida la oriental, de donde proviene la dinastía omeya-, ya nos hizo ser cautos desde un principio.

7 Emblemático castillo califal donde uno de nosotros pudo trabajar durante la campaña de verano de 1984, bajo la dirección de J. Zozaya Stabel-Hansen.

8 En este complejo, bien datado por la inscripción fundacional de mediados del s. X, hay unos pocos fragmentos de paramentos en canteria (AZUAR, 1989a).

9 Aparecen algunas estructuras de este tipo, si bien de escasa entidad, en la Plaça de l'Almoina, en un muro y lindar del sector E, que datan en el s. XI (BADIA; RIBERA LACOMBA, 1999), así como en los basamentos de un posible acueducto, de similar cronología, aparecidos en una excavación de la C/ Sagunt (LERMA, 1998).

10 En el caso de Ifac, son estudiadas por Aranegui-Bazzana (1980), pero su atribución a època andalusí ha sido discutida por Josep Ivars (1987). El mismo Bazzana (1992: 67) es quien aporta los otros ejemplos del uso de la piedra de sillería, especialmente en basamentos y esquinales.

II Lo conservado en Alpont, en comparación con lo que se ha citado, es una obra maestra, sobretodo la torre sur, toda realizada con grandes sillares colocados de través, a sardinel, o atizonados; pero aparte de esta torre, también se conserva en Alpont otro paramento en técnica idéntica, aunque muy erosionado, una cámara subterránea, toda a soga y tizón y, ya fuera del castillo, un arco de ingreso a la población. (RIBERA, 1986).

12 En este sentido son interesantes p.e. VALDES, 1988; MORALES, 1995. 
Aparte de determinados detalles técnicos o arquitectónicos, ya aludidos básicamente en el capítulo descriptivo y que, por comparación con otras obras andalusíes conocidas, podríamos resumir en: el tipo de arcos utilizados, con dovelas largas y estrechas, cuyas juntas tienden a converger en puntos mas bajos que la línea de arranque; que presentan una línea de trasdós bastante irregular y, al menos en un caso, la clave esta muy destacada del resto de las dovelas; el empleo de sillares, asimismo, de tendencia mas bien larga y estrecha que maciza, aparejados a soga y tizón, con frecuentes tizones juntos; el enmarcado o retranqueo del sector central o principal del puente... Considerábamos indispensable intentar aportar otras pruebas, como podrían ser el tratar de contextualizar estos puentes con el espacio y con lo que sabemos del poblamiento, aunque es un camino largo y que, a pesar de los esfuerzos, no da frutos fácilmente ni, menos todavía, argumentos categóricos.

El plano o croquis de situación de los puentes que hemos realizado (Fig. 2), recoge los alrededores inmediatos de Bocairent, tomando como base la red hidrográfica. Se representa lo que conocemos del poblamiento romano y andalusí de esta área, así como los trazados hipotéticos que podrían seguir los caminos ${ }^{13}$.

Por lo que respecta al poblamiento romano, y con las salvedades de ser un conocimiento muy embrionario ${ }^{14}$, se puede ver que los escasos restos de poblamiento romano detectados hasta hoy, especialmente la zona de Massarra-Mas del Pou y, mucho menos sig- nificativos, les Ombries, se encuentran bastante alejados y difícilmente conectables con los puentes en cuestión. En el primer caso se trata de sendas necrópolis tardías, con tumbas de orientación este-oeste, excavadas en la roca, datadas en los siglos VI-VII d. C., la de Mas del Pou con mas de 60 tumbas, y de las que desconocemos los asentamientos o lugares de habitación correspondientes ${ }^{15}$ (RIBERA, 1992; VILLAESCUSA, 200 I). De les Ombries tenemos un escueto registro cerámico de superficie, sin constatar ningún resto estructural, pero que nos permite suponer un amplio periodo cronológico, de los siglos I al IV d.C., por la presencia, entre otras, de sigilata sudgálica, lucente y clara D. Completan el panorama otros dos hallazgos aislados: Bancal Roig y l'Alboret, estos sí, en las inmediaciones de los puentes, pero bastante intrascendentes y de dispar cronología: s. I-II d.C. en el primer caso y s. IV-V, en el segundo.

También cabe decir que fuera del área recogida en el plano, pero cercano, queda un asentamiento romano de mayor envergadura y de amplia cronología, la Casa Alta-Sant Antoni, situado en la zona del Collado, al SE, en el punto de contacto de las dos cuencas fluviales -Clariano y Vinalopó- (s. II-I a.C. a IV-V d.C.); y que al menos debería haber otro asentamiento -por los indicios- entre este de la Casa Alta y el de les Ombries más o menos por la zona de la Lloma-la Casa Glòria ${ }^{16}$. Igualmente fuera del plano pero muy cercano, esta vez al norte, existe otro yacimiento, el Castellaret, asentamiento de altura y fortificado, centrado en los siglos IV-V d.C.

13 Para rebajar densidad al plano, no hemos incluido los caminos actuales, muy distorsionados por las obras de finales del XIX y principios del XX (carretera, ferrocarril), ni tampoco los tradicionales, cuya estructura radial desde el núcleo urbano, no se adecua con el itinerario que parece deducirse de la situación de los puentes en cuestión.

14 No se han hecho estudios de detalle; Nos basamos sobretodo en nuestras prospecciones que, aunque amplias, no son sistemáticas. Reconocemos que es poco y estamos seguros de que, a pesar de las fuertes transformaciones post-medievales que ha sufrido el territorio, todavía hay muchas novedades por aparecer, especialmente para época romana, a la que debe corresponder un poblamiento bastante más intenso del que se desprende de este plano.

I5 También conocemos la existencia de un as de bronce, de llici, de Tiberio, que se atribuye al yacimiento de Massarra, pero por desgracia la fuente de información - guarda del Museo local- no nos merece ningún crédito, después de sufrir reiterados despropósitos.

16 En las proximidades de la Casa la Lloma -o les Llomes-, (fuera de nuestro plano, pero immediata al sw) apareció una cámara subterránea que no se pudo contextualizar; pero en superficie se recogieron algunos fragmentos de cerámica tardo-romana (VILLAESCUSA, 200 I: 299). Por nuestra parte, en la zona de la Casa Glòria, cercana a la anterior, hemos recogido algunos fragmentos dispersos de cerámica romana, básicamente de los s. III- IV. 
En todo caso resulta un tanto sorprendente la escasez de datos correspondientes a época alto-imperial, lo que contrasta con la relativa abundancia para época tardo-romana. De todas formas, y aun con todo lo expuesto anteriormente, no nos parece un poblamiento especialmente intenso o destacado, si lo comparamos por ejemplo con el resto de la comarca de la Vall d'Albaida (RIBERA; BOLUFER, 2000), ni mucho menos, como para explicar por si solo la existencia de los puentes.

Pero debemos suponer que estos puentes obedecían al paso de una vía que interesaba a una organización superior, o estado, para poner en comunicación a las ciudades (en época romana: Saetabis, Dianium y llici, las más próximas). Desde este punto de vista, tanto el puente de Perinos como el de Canyaret constituyen puntos lógicos de un itinerario de paso por el corredor de Bocairent, de una hipotética vía entre la costa y el interior peninsular. Pero en cambio la ubicación del puente de la Frontera, en medio de los barrancos y apartado de aquella vía hacia el valle de Beneixama -Villena, distorsiona esta visión, y no se explica si no es por la existencia de un núcleo urbano o centro destacado, en el lugar donde se localiza la población de Bocairent -o en sus inmediaciones-. Sin embargo, por ahora no tenemos ningún indicio de esto, ni un fragmento de inscripción romana, ni unos simples restos cerámicos..., no sólo del núcleo urbano actual sino de toda la zona próxima ${ }^{17}$.

En época medieval andalusí el panorama cambia bastante. Bocairent -Bukayrân- es citado por diversas fuentes árabes (EPALZA, 1988) y alcanza cierta fama por algunas de sus producciones textiles de lana ${ }^{18}$ (LOMBARD, 1978: 26-28) e incluso de seda (LOMBARD, 1978: 98, n. 2), (MARTINEZ, 1991). Aunque nunca se le cita como medina, según Idrisi es un hisn destacado, bien fortificado, tan poblado como una medina, con un mercado frecuentado, ricos cultivos en sus alrededores y una floreciente industria textil (BAZZANA; CRESSIER; GUICHARD, 1988: 62), (BAZZANA, 1992: 209). Mazzoli la incluye como una ciudad tipo 4, con zoco periódico extramuros, de relativa importancia (MAZZOLI-GUINTARD, 2000: 120). A pesar de esto, solamente conocemos un personaje destacado, Ibn Ruhaim, de época almorávide que fue poeta y ejerció diversos cargos en Sevilla (SANCHIS GUARNER, 1976), (GUICHARD, 1990: Doc. 36). Pese a su proximidad a Xàtiva, casi siempre se la cita como perteneciente a Denia, basándose en Ibn Said (BAZZANA, CRESSIER Y GUICHARD, 1988: 64), (MAZZOLI-GUINTARD, 2000: 361), lo que parece claro $-y$ especialmente relevante para nuestro estudio- al menos en el siglo Xl, por la pujanza de Denia, de la que Bocairent sería una de las principales conexiones o salidas terrestres a las grandes vías del interior peninsular (RUBIERA MATA, 1985: 40).

Los restos arqueológicos, esparcidos por el territorio son abundantes (Fig. 2) y significati$\operatorname{vos}^{19}$. Incluso hay suficiente constancia arqueológica de algún asentamiento de época califal, como els Vilars ${ }^{20}$, a tan solo $500 \mathrm{~m}$ al NE del puente de la Frontera, así como otros indicios -la Canaleta-, muy próximos a la población actual. Otro asentamiento andalusí, de datación más amplia pero imprecisa -básicamente s. XI y Xll- es el de l'Illa ${ }^{2 !}$, muy cercano también al

17 La única excepción que conocemos y que tomamos con las debidas reservas, es la notícia de la aparición de unas "monedas romanas" entre los escombros de las reparaciones de unas casas, hacia 1965, en la zona del núcleo urbano conocida como Porxe de la Calçà (VAÑÓ, 1978).

I 8 Lombard, tomando la cita Idrisi, traducida por Dozy, las describe como ...des solides, moelleuses et précieuses étoffes de Bocairent... souples et blanches comme le papier...

19 Nos basamos en nuestras prospecciones, tanto las oficiales como las derivadas del trabajo habitual del museo comarcal. No conocemos otros estudios al respecto.

20 Este yacimiento, por desgracia estructuralmente arrasado, ha proporcionado un buen conjunto de materiales cerámicos básicamente del s. X, entre los cuales numerosos fragmentos decorados en verde y manganeso. Una reciente actuación de urgencia, motivada por la urbanización del sector más próximo al casco urbano, y todavía en estudio, documentó un vertedero con restos coetáneos, consiguiendo contextualizar los materiales de superficie, pertenecientes a un asentamiento totalmente destruido.

21 Hasta el momento no conocemos restos estructurales de este yacimiento, (aparte de algunos silos eneolíticos), pero los fragmentos cerámicos andalusíes son abundantes y aparecen dispersos por una amplia zona en la punta de l'Illa. 
mismo puente de la Frontera, pero en el lado este. De cronología igualmente imprecisa, por el momento, pero dentro del mundo andalusí, son los grupos de silos subterráneos de els Corrals, excavados en la roca, y los de Possolo, quizás mas antiguos los de este último grupo (s. X-XI?) que el anterior (s. XI-XII?). También a los siglos XI-XII, básicamente, debe corresponder la ocupación de la Cova de la Mola.

Mas claramente del periodo Almohade es el gran asentamiento del Alt de la Frontera, de cerca de 0,5 Ha de extensión y con abundantes restos estructurales, basamentos de muros trabados con mortero de cal, etc. que debe corresponder, por su ubicación, a la alquería de Benicalàs, citada por la documentación cristiana del s. XIII (FERRANDO, 1979). Otros puntos dispersos por el territorio, si bien sin concentraciones de alguna consideración y de variada cronología son: l'Alboret ${ }^{22}$, inmediato al puente de Perinos, l'Alqueria -posible alquería de Lex, del Repartiment-, els Casals, les Ombries, la Casa Glòria y Rambleta. Mención aparte merecen los extraordinarios grupos de graneros de acantilado o coves-finestra (RIBERA; BOLUFER, 1994), abiertos en los cortados roqueros de toda la cabecera del río Clariano, 8 de los cuales en termino de Bocairent, 4 en el entorno inmediato del núcleo medieval, con su grupo mayor de les Covetes dels Moros, y otros cinco grupos mas al norte, en los términos de Alfafara y Ontinyent. A pesar de su relevancia y vistosidad deben obedecer a alguna oleada muy concreta de asentamientos beréberes de hacia el siglo X, y en la mayoría de los casos su uso o continuidad no prosperó.

Cabe decir todavía que, fuera de la zona concreta que se representa en el mapa, pero den- tro del termino de Bocairent y aledaños, encontramos muchos otros lugares con restos de época medieval andalusí, entre los cuales y como más destacados citaremos el Castellar, al norte, y l'Ereta dels Moros, al sur, ambos con muralla y del s. $X$ si no anteriores; así como el Castellet de Mariola y les Torretes del Vinalopó, (TORRO: SEGURA, 1985), también con alguna fortificación y de los últimos siglos del periodo. Con estos se completa un panorama de largo e intenso poblamiento andalusí en el entorno de Bocairent.

Pero a pesar de esto, todavía no sabemos casi nada del espacio concreto que ocuparía Bocairent ni de sus aspectos físicos ${ }^{23}$; contrariamente a lo que se cree, se conoce bien poco - o nada- de elementos claramente andalusíes en el llamado barrio medieval ${ }^{24}$.

¿Quizás en el castillo que habría en la parte más alta, donde ahora se encuentra la iglesia, existieron también algunos restos paralelizables a los puentes? Probablemente no lo sepamos nunca; pero parece evidente que la construcción de esta serie de puentes debería estar relacionada con la adecuación de los accesos al hisn de Bocairent y, seguramente, también con el paso de un camino entre la costa -Deniay el interior peninsular.

Este probable camino vendría desde Denia, puerto destacado y capital de la Taifa en el s. $X \mathrm{l}$, por la Vall de Gallinera, inmediaciones de Cocentaina, Agres, hasta Bocairent y continuaría, hacia el interior y sur peninsular por BiarVillena. No obstante no conocemos ningún itinerario árabe que hable expresamente de esta vía, ni tampoco se incluye ninguna mención de relevancia en los más próximos estudios histo-

22 L'Alboret és un pequeño caserío, con una copiosa fuente, situado a 200 m al este del puente de Perinos. Según Rubiera este topónimo hace referencia al étimo árabe al-Barid, posta, -diminutivo al Burayd- lo que seria una prueba mas del paso de una vía árabe (RUBIERA MATA, 1985b: 16, 22), de la que el puente inmediato formaria parte.

23 Una especie de aproximación realizó F. Franco (FRANCO, 1991), pero al no basarse sino en unos cuantos tópicos sin fundamento y en esquemas apriorísticos, los resultados nos parecen bastante decepcionantes.

24 A pesar de nuestro interés, la servitud de las actuaciones de urgencia, entre otras causas, impidieron nuestro trabajo de investigación en el núcleo urbano de Bocairent en ocasión de unas recientes obras de renovación urbanística del mismo, por lo que apenas se ha avanzado en este sentido. 
riográficos -con la excepción de Rubiera ${ }^{25}$-, o arqueológicos ${ }^{26}$. En cambio sí que hay referencias al camino de Murcia a Valencia, ya en el s. XII (ABID MIZAL, 1989), que pasaría por Biar y Ontinyent, ignorando si atravesaría la sierra por la Vall Seca, o si pasaba por Bocairent ${ }^{27}$, como afirman algunos autores (RUBIERA MATA, 1985).

Sea como fuere, entrando en detalle en el sector de camino que nos ocupa, viniendo de levante encontramos en primer lugar el puente de Perinos y después de seguir 1,5 Km por el mismo nivel o cota, encontramos el puente de Canyaret. El caso es que viendo cómo se mantiene la cota entre los puentes conocidos (620/630 m snm en los tres), parece razonable pensar que si el interés no fuese entrar en Bocairent el camino seguiría hacia el suroeste, siguiendo aproximadamente esa cota, hacia la zona del Collado, Sant Antoni de Dalt, camino señalado con la letra $A$. No resulta convincente que se diera un rodeo tan grande para acceder a Bocairent, y más si tenemos en cuenta que no debería tratarse de un camino para carros - como más adelante matizaremos- y por tanto no debería ser determinante el mantener la cota 0 buscar pendientes suaves. Hemos de pensar por tanto que en algún punto de este trayecto hacia el SE, el camino giraría para entrar en Bocairent -para después salir hacia poniente precisamente por el puente de la Frontera. Hemos incluido en el plano dos posibilidades, resultado de la observación minuciosa de los accidentes geográicos de toda esta zona, y del reconocimiento del terreno llevado a cabo por nosotros. La primera y más razonable posibilidad -señalada con la letra BI-, sería que el camino, poco después del puente de Canyaret bajara por la foia d'en Palau y, buscando el actual camino de Sant Jaume, se dirigiera a cruzar el río por las proximidades del puente de Mitja Calça, desde donde subiría hasta la actual plaza dels Olmets, sitio donde vendría a enlazar con el camino de salida hacia poniente, señalado con la letra C. La otra posibilidad apuntada, señalada con la letra B2, sería la desviación aproximada en la fuente del Retiro y, siguiendo este barranco por su margen izquierdo, llegaría poco más o menos donde ahora cruza el río el puente de la Canaleta, desde donde seguiría de forma parecida a la descrita para la anterior posibilidad. En contra tiene esta segunda posibilidad, el gran rodeo que se da, si venimos del Este, pero a favor tiene el topónimo el Pontarró -sin duda haciendo referencia a un viejo puente existente en esta área-. Y también el hecho de que, salvando este barranco por su cabecera, se consigue un camino más largo pero más suave ${ }^{28}$.

25 Esta autora, en una de las obras citadas (1985a), menciona la existencia de esta vía de Denia a Bocairent, como única salida terrestre de Dénia, pero sin embargo pone mayor énfasis en otro camino que también pasaría por Bocairent: la que denomina "vía augusta", puesto que la supone continuación de la de época romana, y que enlazaría Xativa y Biar, como parte del camino de Murcia a Valencia. En su otra obra (RUBIERA, 1985b) da muchos mas detalles, bien documentados, de esta vía augusta o, mejor, vía mayor de los árabes, a la que nada tenemos que objetar para época medieval pero sí en cambio para época romana. Existiendo un valle tan accesible como el del Cànyoles nos resulta poco verosímil que en época romana la vía augusta, desde Saetabis, cruzara por Olleria - Ontinyent con sus dificilísimos pasos -impracticables para carros hasta finales del s XIX- para ir a salir a Villena (donde Rubiera ubica ad Turres), siendo que el interés de la vía romana era tanto o mas que llegar a Cartagena, proseguir hacia la Mancha -Saltigi- en dirección a Castulo etc., lo que se consigue mucho mas efectivamente (camino natural sin accidentes de consideración y mas corto) por el valle del Canyoles hasta Caudete. El cambio en este tramo concreto de vía en época medieval andalusí, -indiscutiblemente reflejado en las fuentes árabes-, especialmente a partir del s. Xl, se explicaría tanto por el flujo de transito -que debía ser mucho más intenso entre Murcia y Valencia que con el interior peninsular-, como por el interés en incorporar los nacientes núcleos urbanos andalusíes (como Ontinyent y Bocairent, p.e.) cabezas de zonas mas densamente pobladas y, por supuesto, por el própio carácter del transporte, a base de caballerias -sin carros-, que podía cruzar los estrechos senderos de los puertos de la Serra Grossa y Serra d'Agullent.

26 Azuar sí que hace alguna mención de esta ruta, pero como una posibilidad mas; De hecho no la incluye en su mapa de comunicaciones de los siglos XI-XIII (AZUAR, 1989b, p. 356).

27 Si así fuera, el camino quizás aprovechara esta infraestructura anterior y, desviándose hacia el norte a la altura de Alfafara, buscara Ontinyent por el puerto de la Casa Bona, en vez de enfilar por el difícil camino de el Castellar. Pero los autores que citan el paso por Bocairent deben basarse en otras versiones de Idrisi, ya que en la edición de Abid Mizal que consultamos nosotros no aparece nunca Bocairent, sinó siempre Ontinyent en su lugar. Tan solo se alude al rio Bkar, que debe hacer alusión al rio de Bocairent, actualmente rio Clariano-Albaida.

28 También cabe tener en cuenta que este interesante puente de la Canaleta parece ubicarse en un lugar propicio para atravesar el río, como lo demuestra su uso actual y las cuatro ampliaciones que se le han ido adosando desde el s. XVI-XVII momento del que debe datar la obra mas antigua que ara se puede observar. También hay todavía alguna otra posibilidad, como sería cruzar por otro paso cerca de la Font del Borreguet, etc. 
En cualquier caso, y como venimos diciendo, la ubicación del puente de la Frontera creemos que es decisiva para apoyar la cronología andalusí de toda esta serie de puentes.

Partiendo de la base de que el núcleo urbano actual de Bocairent tiene su origen en época andalusí y no en época romana, -tal y como ocurre en muchos otros casos de la zona; por ejemplo en el caso de la vecina Ontinyentcomo lo evidencian tanto las menciones documentales en las fuentes árabes, así como, mientras no se demuestre lo contrario, todos los datos arqueológicos disponibles; la existencia de este puente no tendría ningún sentido, en un lugar tan accidentado, en medio de barrancos y apartado de la via natural más accesible - camino A-, que solamente se explica para poder acceder/salir al sector del núcleo urbano de Bocairent, en un peñón fácilmente defendible por los profundos barrancos que lo circundan y, a la vez, verdadero cul de sac, hasta el momento en que se construya el puente de darrere Vila ${ }^{29}$.

Así las cosas nos reafirmamos en que si esta vía que soportan los puentes se hubiera concebido en época romana, del puente de Canyaret hubiera seguido, a poniente, hacia la Lloma y Sant Antoni de Dalt, -camino A- sin desviarse ni entrar para nada hacia Bocairent -que no existiría, como núcleo urbano ni, por tanto, tampoco este puente de la Frontera.

Aunque la anchura de los puentes, con bastante más de $2 \mathrm{~m}^{30}$, debería permitir el paso de carros, curiosamente el uso de los carros está muy mal documentado en al-Andalus, siendo las caballerías -y en especial las reatas de asnosla base del transporte terrestre; cosa que contrasta con el mundo romano e incluso con el ibérico ${ }^{31}$. Un detalle más a tener en cuenta, junto a que lo que salvan son pequeños barrancos bastante intrascendentes, como para que no se justifique mucho la realización de estos puentes. Parece que estaríamos mas bien ante una representación del poder; de unas obras prácticas sí, pero también -y quizás sobretodo- de prestigio. Otra cuestión es: ipero de qué poder? ¿de un poder local ignoto? ¿del de los primeros momentos de la Taifa de Denia? ¿del estado Califal? Por ahora no tenemos respuesta. Pero en este sentido, debe haber arquitectos del núcleo cordobés, cercanos al poder, que van de un lugar a otro, acompañando a las expediciones califales, dirigiendo construcciones. De hecho, aparte de las crónicas cordobesas, hay alguna noticia expresa de estos movimientos, si bien de las épocas inmediatamente posteriores ${ }^{32}$ (TORRES BALBÁS, 1982). Esto podría explicar la aparición de algunas obras aisladas, con estas técnicas y detalles constructivos, por toda la península e incluso, como se ha visto últimamente, también en el norte de África ${ }^{33}$. Tampoco se puede descartar, en este mismo sentido de la ejecutoria de las obras, la diáspora de poetas, artistas y artesanos que se produce en Córdoba, en la últimas décadas del Califato, haciendo emigrar a un gran número de intelectuales que se repartirían por diferentes taifas, entre ellas las del Xarq, y especialmente la de Denia (RUBIERA MATA, 1985a: II5 y ss.).

29 Aunque también se ha calificado de romano, éste puente de darrere Vila tiene una factura claramente bajo-medieval. A pesar de no haber podido localizar documentación sobre el momento exacto de su construcción, sabemos que ya estaba construido el I564. en que es citado por Viciana en su crónica (VICIANA, Ed. 1972: 365). Tampoco se ha podido encontrar vestigio alguno de la existencia de otro puente precedente en el mismo lugar y aunque pudiera haber existido un paso en el mismo emplazamiento, creemos que, caso de existir en época andalusí, almenos en determinado momento, éste seria de poca importancia, entre otras razones por la ubicación de un grupo de graneros de acantilado en su inmediatez, siendo que estos grupos de graneros suelen situarse en lugares fuera de la vista y poco frecuentados, precisamente como estrategia fundamental para su seguridad.

30 Quizás 5 I/2 codos ma'muni $(5,5 \times 0,47 \mathrm{~m})$ ?. Hemos renunciado a reducir metrológicamente las medidas de los puentes a pies romanos o codos islámicos porque se pueden encontrar tantas coincidencias como con palmos y varas valencianos, p.e.

31 Excepcionales caminos de carro de época ibérica se pueden ver por ejemplo en el yacimiento de Meca (Ayora) (BRONCANO Y ALFARO, 1997), o en el Tolmo de Minateda (Hellín) (GUTIERREZ LLORET, 1996), por citar algunos ejemplos próximos.

32 Según parece, siendo rey de Valencia el fata Abd Al-Aziz, nieto de Almanzor, construyó en Valencia un puente de piedra en la salida oriental de la ciudad, camino de Tortosa (RUBIERA MATA, 1985a: 35).

33 Concretamente la fortaleza de Hayar al-Nasr (TORREMOCHA; ELBOUDJAY, 200I), en algunos aspectos constructivos idéntica a Alpont. 
Incluso se puede pensar que existieran muchos más puentes parecidos por toda nuestra geografía, pero mientras que los puentes situados más abajo de las cuencas habrían desaparecido por las sucesivas avenidas, y en todo caso sustituidos por otros, en Bocairent determinados factores, como el que son puentes sobre barrancos muy secundarios, de poco empuje, que se encuentran en las cabeceras, y que han sido reforzados y mantenidos en un uso u otro, son todas circunstancias que han confluido para que se hayan podido conservar hasta hoy, al menos mil años después de su edificación.

\section{BIBLIOGRAFÍA}

ABID MIZAL, J. ( 1989): Al-Idrisi. Los caminos de al-Andalus en el siglo XII. CSIC. Madrid.

ACIEN ALMANSA, M. (1987): "Madinat al-Zahra en el urbanismo musulmán". Cuadernos de Madinat al-Zahra, I.

ARANEGUI, C.; BAZZANA, A. (1980): "Vestiges de structures defensives d'époque romaine tardive et d'époque musulmane au Peñom d'lfac". Melanges Casa Velazquez XVI. Madrid. Pp.42I-436.

ARJONA CASTRO, A. (1997): Urbanismo de la Córdoba Califal. Córdoba.

AZUAR, R. (1989a): La rábita califal de la duna de Guardamar. M. A. A. Alicante.

AZUAR, R. (1989b): Denia islámica. Arqueología y poblamiento. IC-JGA. Alicante.

BADIA, Angels; RIBERA, Albert (1999): "Plaça de l'Almoina". En CD Memorias arqueológicas y paleontológicas de la Comunidad Valenciana, núm. O. Generalitat Valenciana.

BAZZANA, André (1988): "Les chemins d'al-Andalus et leurs chateaux d'apres le géographe al-Idrisi (Xie-Xlle siècles)". Chateaux, routes et rivières. Actes des Rencontres d'archéologie et d'histoire en Périgord. Bordeaux, pp. 29-44.

BAZZANA, A.; CRESSIER, P.; GUICHARD; P. (1988): Les châteaux ruraux d'al-Andalus. Histoire et archéologie des Hususn du sud-est de l'Espagne. Madrid.

BAZZANA, André (1992): Maisons d'al-Andalus. Habitat medieval et structures du peuplement dans l'Espagne orientale. Casa de Velásquez. Madrid.

BRONCANO, S.; ALFARO, MM. (1997): Los accesos a la ciudad ibérica de Meca mediante sus caminos de ruedas. TV-SIP, 92. València.
COOK, M. (1998): Medieval bridges. Shire Archaeology, $n^{\circ} 77$. Buckinghamshire, UK.

EPALZA, Mikel de (1988): "La Vall d'Albaida musulmana". Estudis i documents - IV. Ontinyent. Pp. 17-24.

FERRANDO, A. (Ed.) (1979). Llibre del Repartiment de València. Valencia.

FRANCO, F. (199|): "Estudio comparativo del urbanismo islámico de seis poblaciones..." Simposio La Ciudad Islámica. I.F.C. Zaragoza. Pp. 353-375.

GARAU LLOMPART, I. (1990): El pont de Suria: un ejemplo de construcción medieval (1420-1421). Mallorca.

GUICHARD, Pierre (1990): Les Musulmans de Valence et la Reconquête (Xle-XIlle Siècles). IFD. Damas. T. I, pp. I9I i ss., Doc 36.

GUTIERREZ LLORET, S. (1996): La Cora de Tudmir... Casa de Velazquez 57. Madrid-Alacant. Vid especialmente pp. 243 y ss, 322 y ss.

IVARS PERES, J. (1987): "El lloc d'lfac. Una fundació del segle XIII". Xàbiga-2. Xàbia. pp. 35-4I

LEONHARDT, Fritz (1986): Ponts; Puentes. P.P.R. Lausanne.

LERMA, Josep-Vicent (1998): "El territorio de la ciudad: la huerta, alquerías y almunias". En: Ribera, Albert (Coord.): 50 años de viaje arqueológico en Valencia. Ajuntament de València. P. 80.

LIZ GUIRAL, J. ( 1985): Puentes romanos en el convento jurídico caesaraugustano. Zaragoza.

LOMBARD, Maurice (1978): Les textiles dans le monde musulman Vlle-Xlle siècle. Paris.

LOPEZ CUERVO, S. (1985): Medina Az-Zahra. Ingenieria y formas. Madrid.

MARTINEZ, M. (1991): "La seda en Murcia: Decadencia y reactivación de una actividad musulmana" Simposio La Ciudad Islámica. I.F.C. Zaragoza. Pp. 465-47I.

MAZZOLI-GUINTARD, C. (1988): "Un pont sans pareil: le pont de Cordoue". Chateaux, routes et rivières. Actes des Rencontres d'archéologie et d'histoire en Périgord. Bordeaux, pp. II - 27.

MAZZOLI-GUINTARD, C. (2000): Ciudades de al-Andalus. España y Portugal en la época musulmana (S. VIII-XV). Ed. Almed. Granada.

MORALES MARTINEZ, A.J. (1995): "A la sombra de Damasco. Arquitectura en Al-Andalus hasta la proclamación del Califato de Córdoba". La arquitectura del Islam occidental. El legado andalusí; Granada. Pp. 43-5I.

PAVON MALDONADO, B. (1990): Tratado de arquitectura Hispanomusulmana. I Agua. CSIC. Madrid.

PAVON MALDONADO, B. (1999): Tratado de arquitectura Hispanomusulmana. II Ciudades y fortalezas. CSIC. Madrid. 
RIBERA, Agustí (1986): "El Castell d'Alpont...". Actas I Congreso arqueologia medieval española. T. III. Zaragoza. pp. 249-279.

RIBERA, A. (1992): "Necrópolis romanes de la Vall d'Albaida". Almaig -VIII. . Ontinyent. Pp. 6I-66.

RIBERA, A. ; BOLUFER, J. ( 1994). "Coves finestra de cingle al País Valencià". Actas del IV Congreso de Arqueología Medieval Española. T. III. Alicante. Pp. 625-643.

RIBERA, A.; BOLUFER, J. (2000): "La romanización en la comarca de la Vall d'Albaida". Actas do 3 Congresso de Arqueologia Peninsular. Vol VI, Adecap. Porto. pp. 197 214.

RIBERA, A.; PASCUAL, J. (en prensa): "Els ponts andalusins de Bocairent". Revista de Festes de Sant Agustí. Bocairent.

RUBIERA MATA, M.J. ( 1985a): La Taifa de Denia. IC-JGA. Alacant

RUBIERA MATA, M.J. (1985b): Villena en las calzadas romana y árabe. Villena.

SANCHIS DEUSA, C. 1994. Els ponts valencians antics. Conselleria d'Obres Públiques. Valencia.

SANCHIS GUARNER, M. (1976): "Cançons mossàrabs en poemes del bocairentí lbn Ruhaim". Revista de Festes de Sant Blai. Bocairent.

TORRO, J.; SEGURA, J.M. (1985): Torres i castells de l'Alcoià-Comtat. Alcoi.

TORREMOCHA, A.; ELBOUDJAY, A. (200I): "Vestigios omeyas en las dos orillas del estrecho". En El Esplendor de los Omeyas cordobeses. Exposición. Fundación El Legado Andalusí. Granada. Pp. 294 -30I.

TORRES BALBAS, L. (|98I): "El puente de Guadalajara. Crónica arqueológica de la España musulmana - VIl". Obra dispersa I, Al-Andalus. Instituto de España. Madrid. pp. 223-232.

TORRES BALBAS, L. (1982): "Arquitectos andaluces de las épocas almorávide y almohade. Crónica arqueológica de la España musulmana - XVIII". Obra dispersa I, Al-Andalus, 3. Instituto de España. Madrid. pp. I79-I89.
TORRES BALBAS, L. (1987): "Arte Hispanomusulmán hasta la caída del califato de Córdoba". Història de España - V, Dir. R. Menéndez Pidal. 5ª Ed. Pp. 331-788. Madrid.

VALDES FERNÁNDEZ, F. (1988): "Arqueología de alAndalus, de la conquista árabe a la extinción de las primeras taifas". Historia General de España y América. T. III. Madrid. Pp. 549 y ss.

VALLEJO TRIANO, A. (1995): "El proyecto urbanístico del estado califal: Madinat al-Zahra". La arquitectura de Islam occidental. El legado andalusí; Granada. Pp. 69-8I.

VALLEJO TRIANO, A. (200I): "Madinat al-Zahra, capital y sede del Califato omeya andalusî". El Esplendor de los Omeyas Cordobeses. Estudios. El legado andalusí. Granada. Pp. 386-397.

VAÑÓ SILVESTRE, F. (1978): "Toponímia bocairentina en la época de Jaime I". Crónica de la XI Asamblea de Cronistas Oficiales del Reino de Valencia. Valencia. Pp. 287-298.

VAÑÓ SILVESTRE, F. (1988): "Los cinco puentes antiguos de Bocairent". Estudis i Documents -IV, La Nostra Terra. Ontinyent. Pp. 7|-8|

VICIANA, Martín de (I564): Crónica de la ínclita y coronada ciudad de Valencia - III. Reedición facsímil de 1972. Universidad de Valencia, Dep. Historia Moderna. Valencia.

VILLAESCUSA GONZÁLEZ, R. (200I): El mundo funerario romano en el País Valenciano. Madrid-Alicante.

VILLARRUBIA, I. ; SATORRES CALABUIG, MA.; SATORRES CALABUIG, V. (1989): "Els nostres noms de lloc". Revista de Festes de Sant Blai. Pp. 109-123. Bocairent

W.AA. (1996): Strade romane, ponti e viadotti. Atlante temático di topografía antica-5. Roma.

ZOZAYA STABEL-HANSEN, J. (1988): "Evolución de un yacimiento: el castillo de Gormaz". Castrum 3. Guerre, fortification et habitat dans le monde méditerranéen au moyen age. CV-EFR. Mâcon. Pp. 173-178.

ZOZAYA STABEL-HANSEN, J. (200I): "Gormaz, portento de fortalezas". El Esplendor de los Omeyas Cordobeses. Estudios. El legado andalusí. Granada. Pp | | 2 - I 17 . 

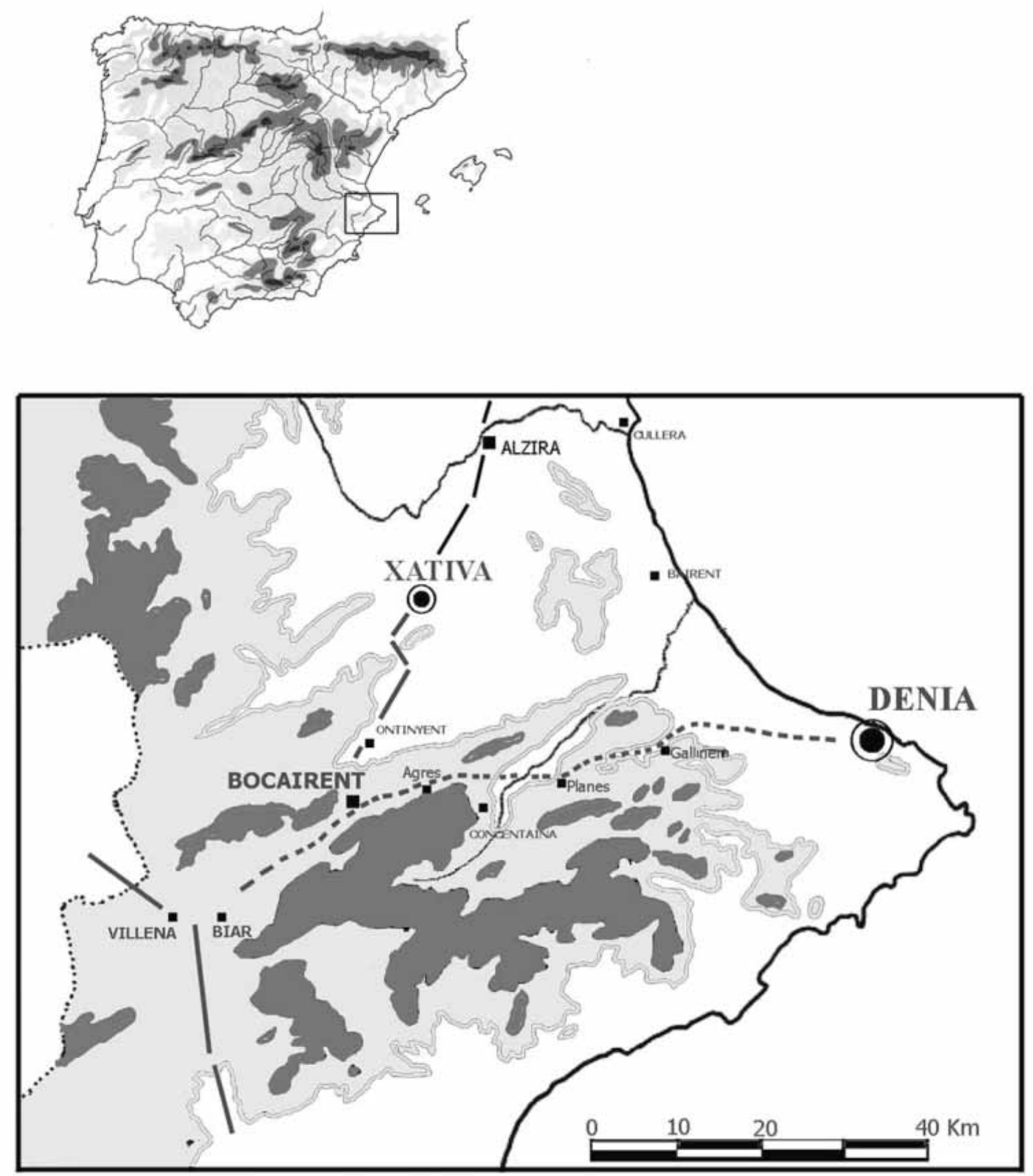

Fig. I. Mapas de situación y localización 


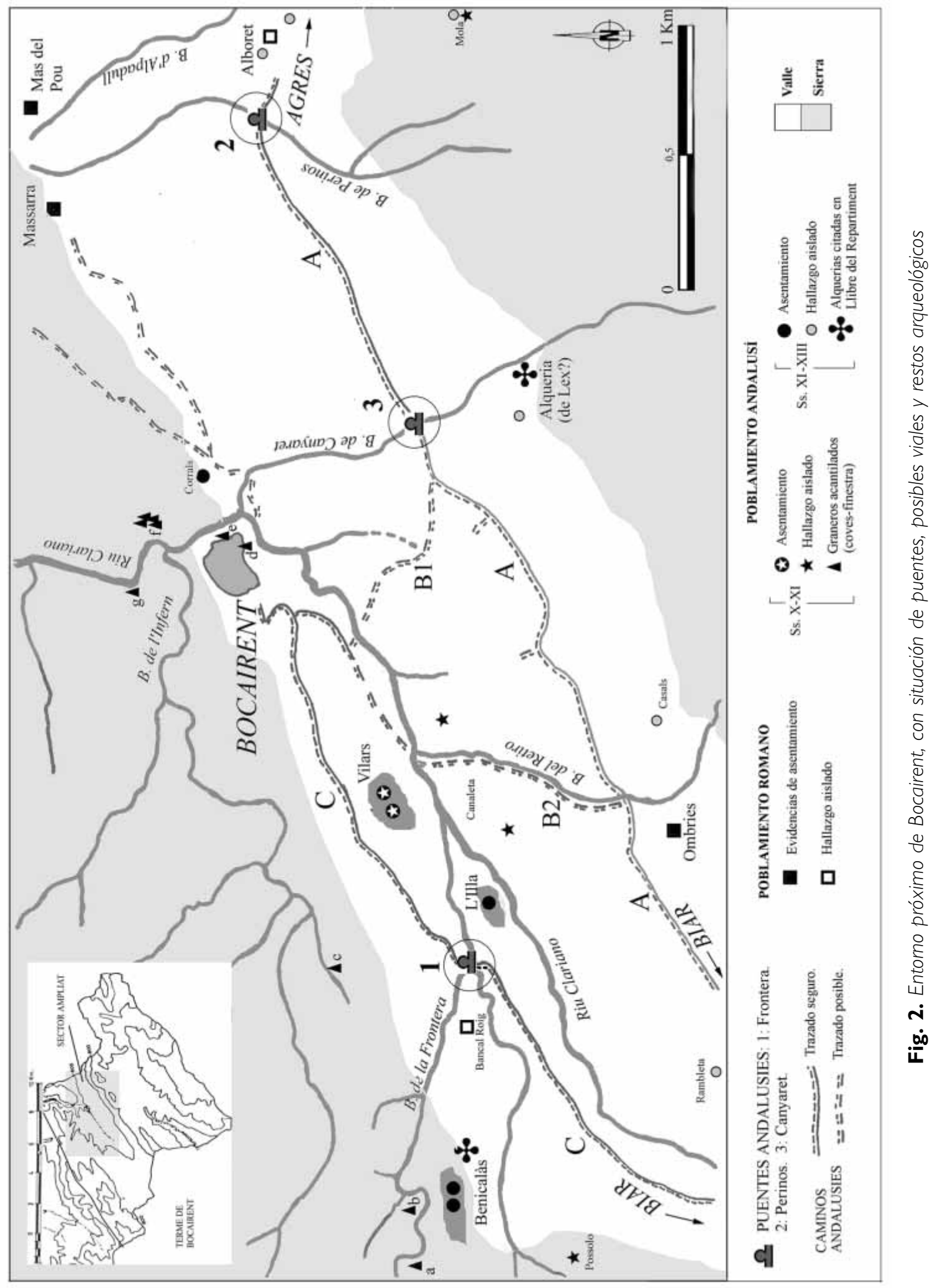




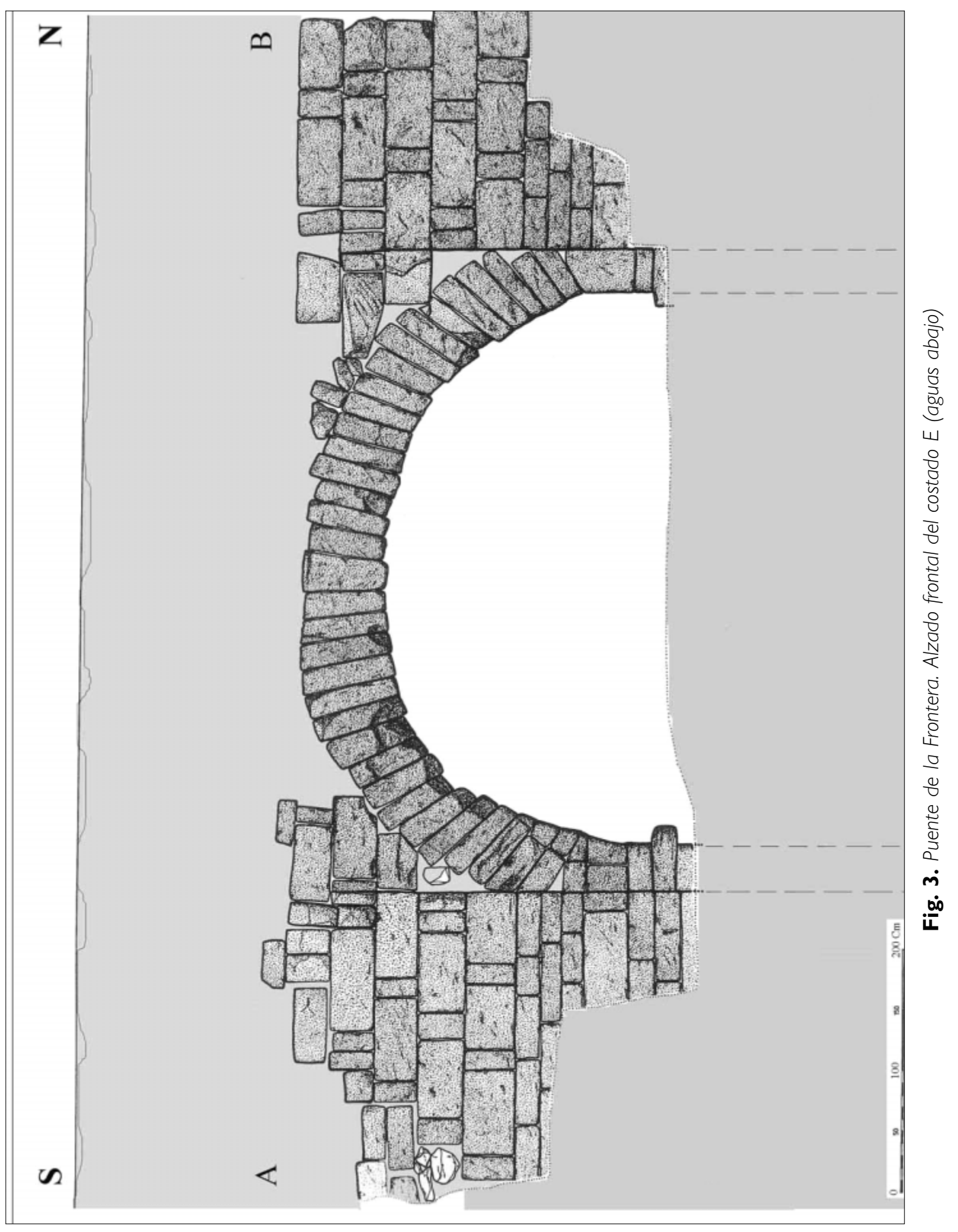




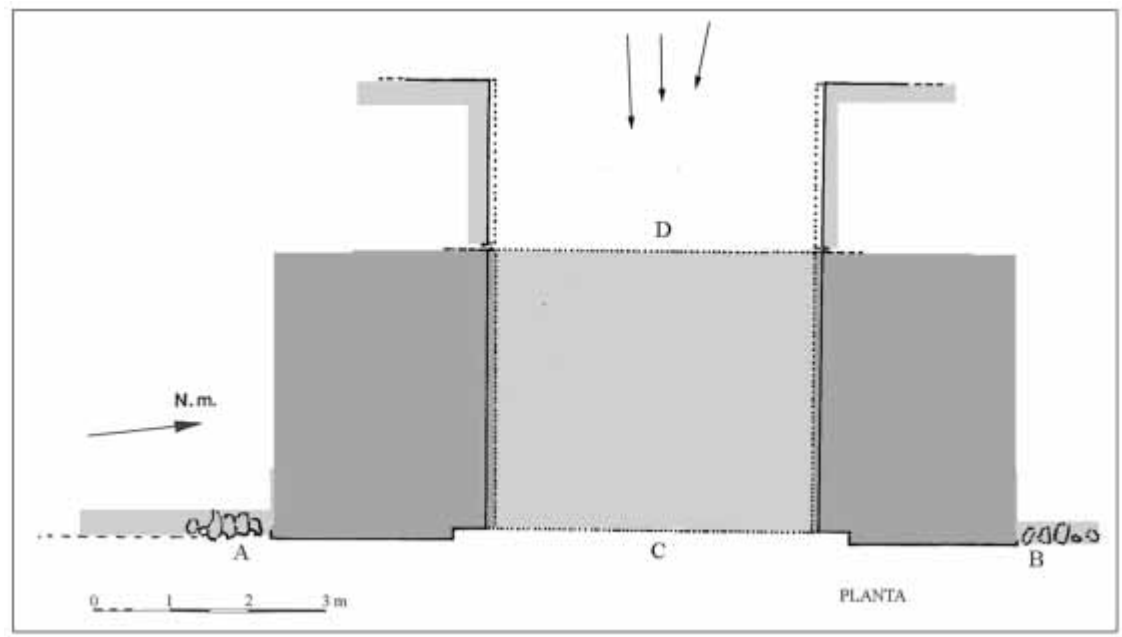

Fig. 4. Puente de la Frontera. Esquema de la planta

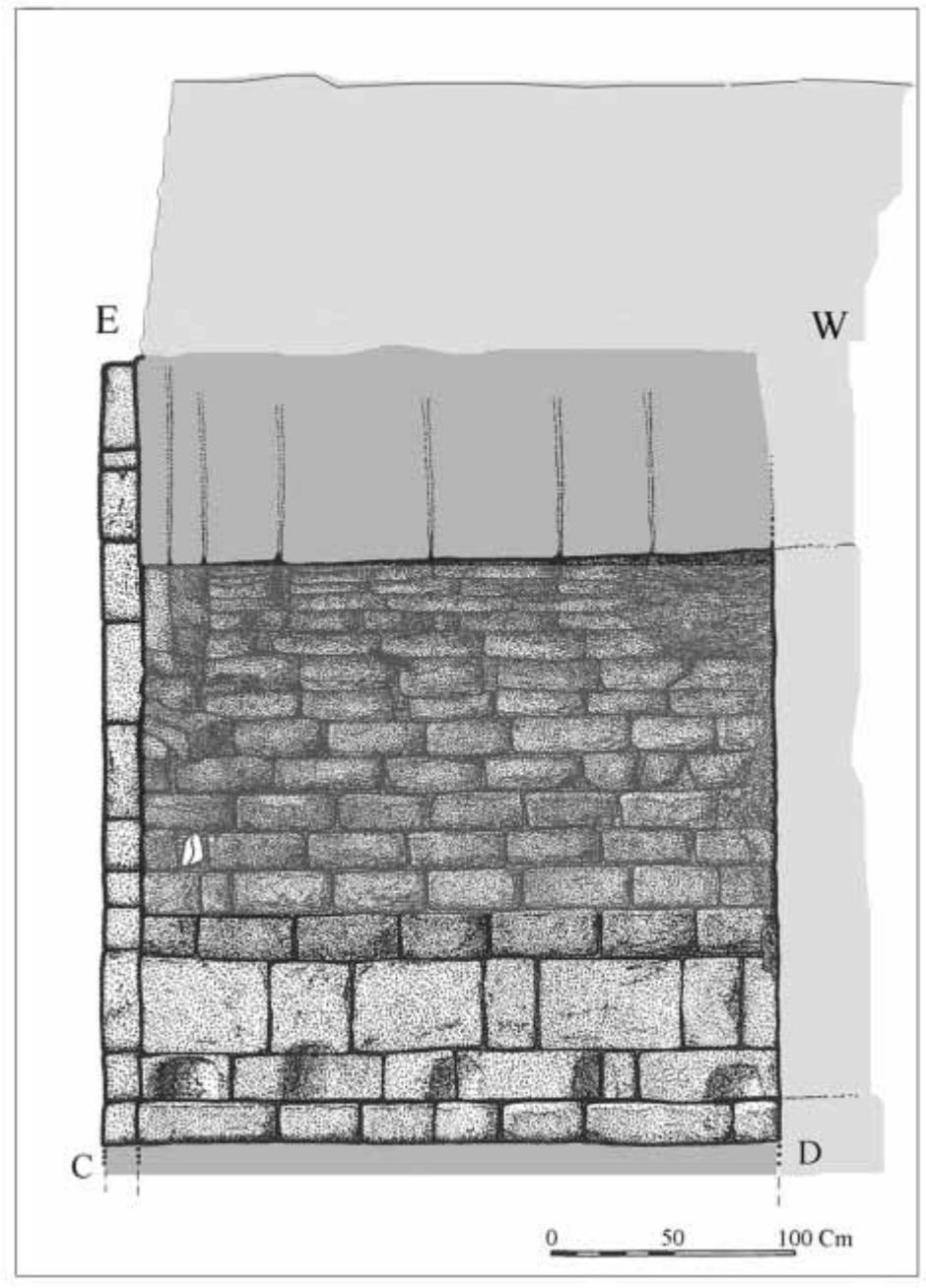

Fig. 5. Puente de la Frontera. Sección E-O (costado sur) 


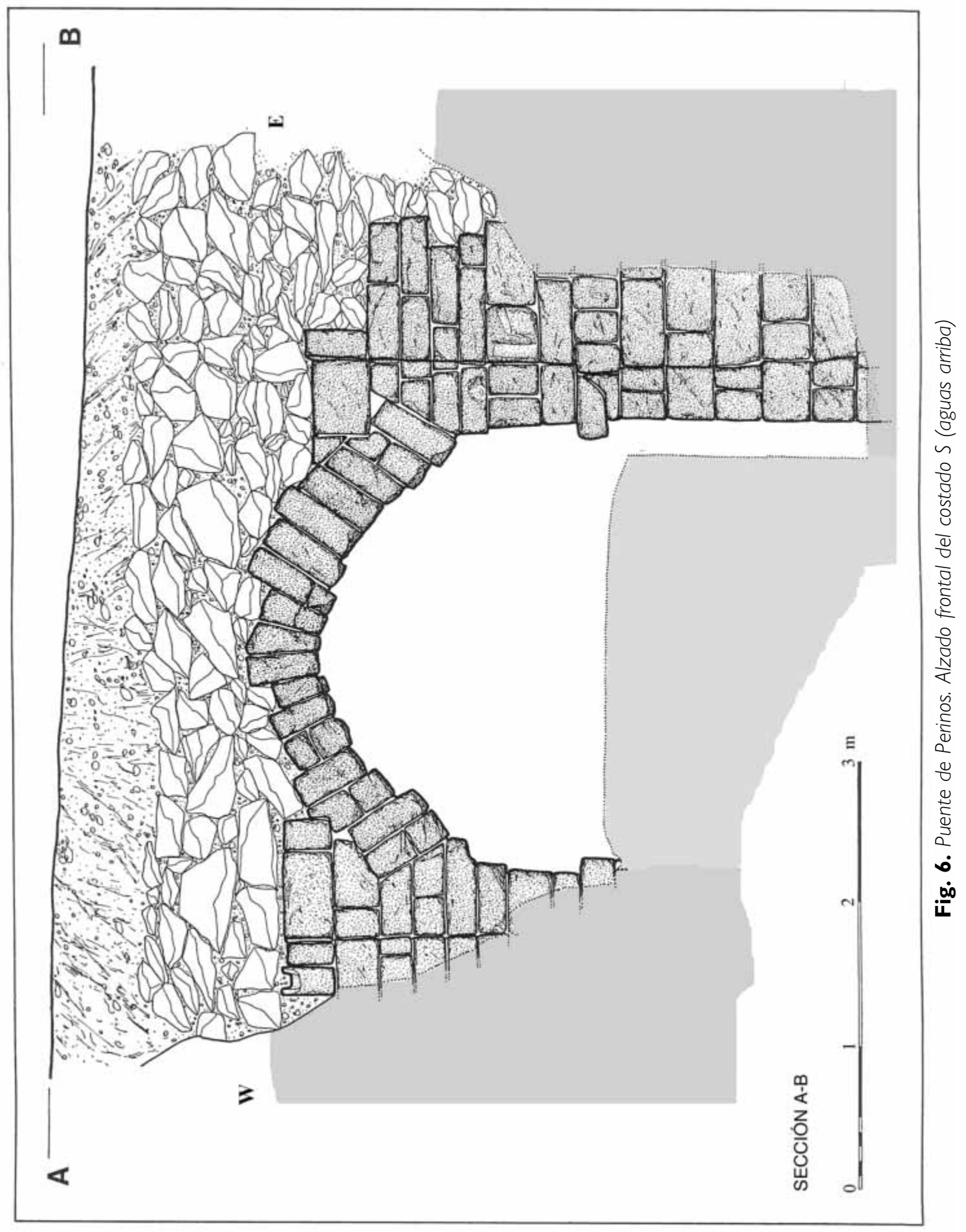




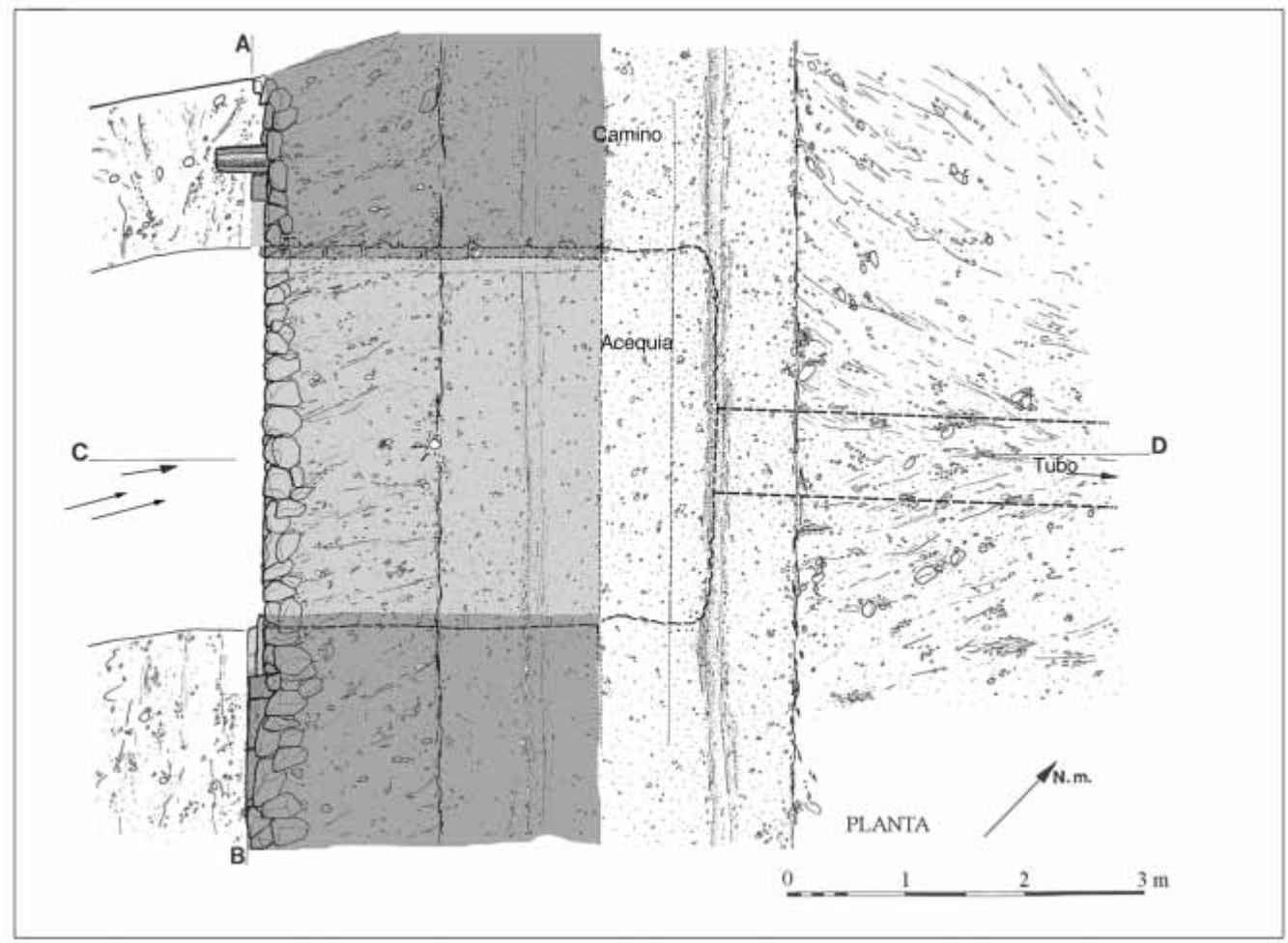

Fig. 7. Puente de Perinos. Planta

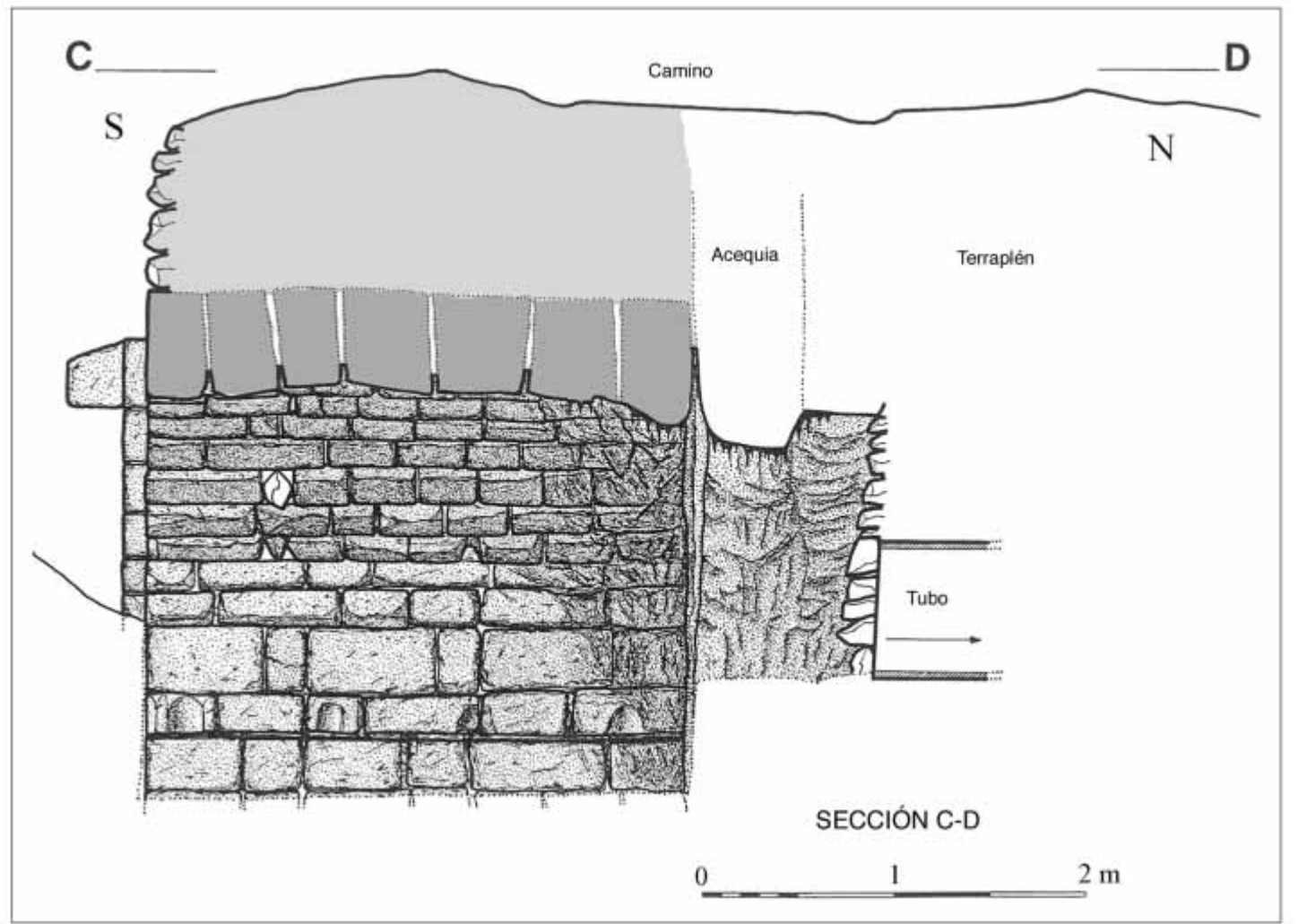

Fig. 8. Puente de Perinos. Sección S-N (costado oeste) 

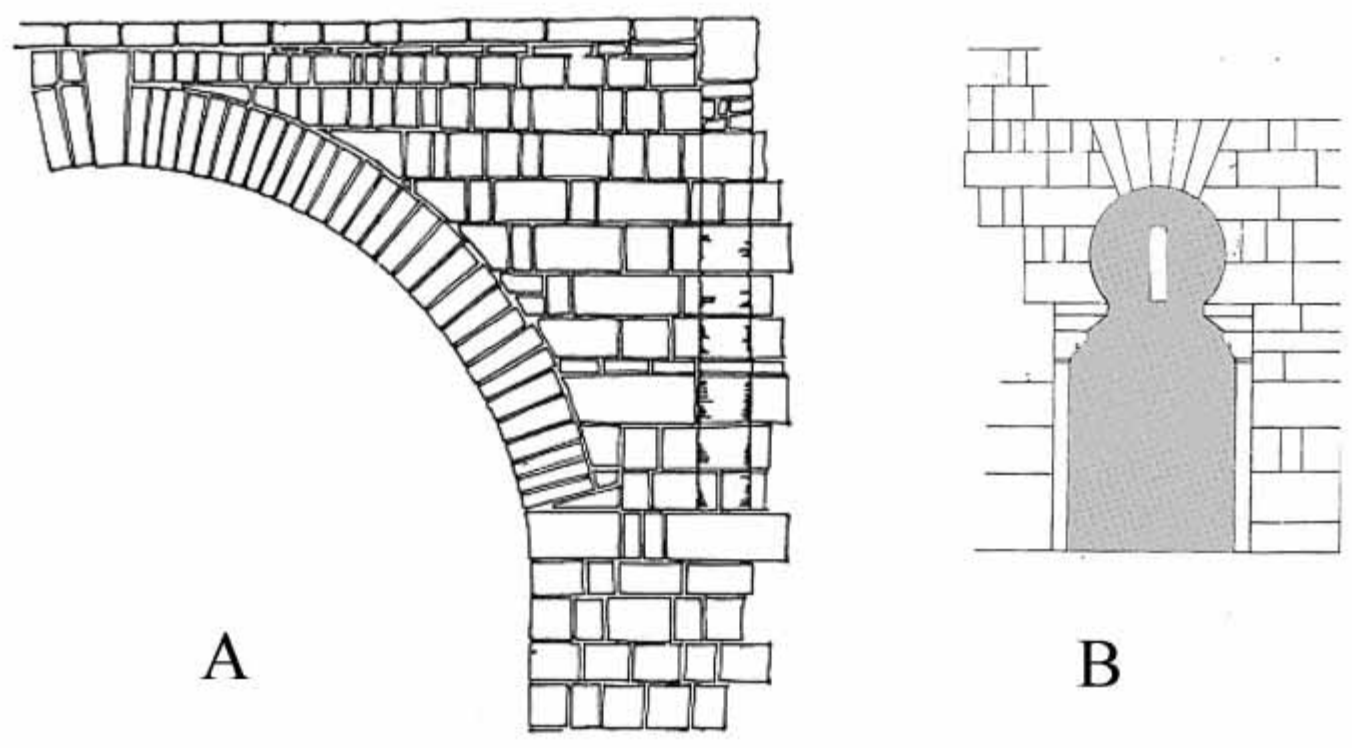

B
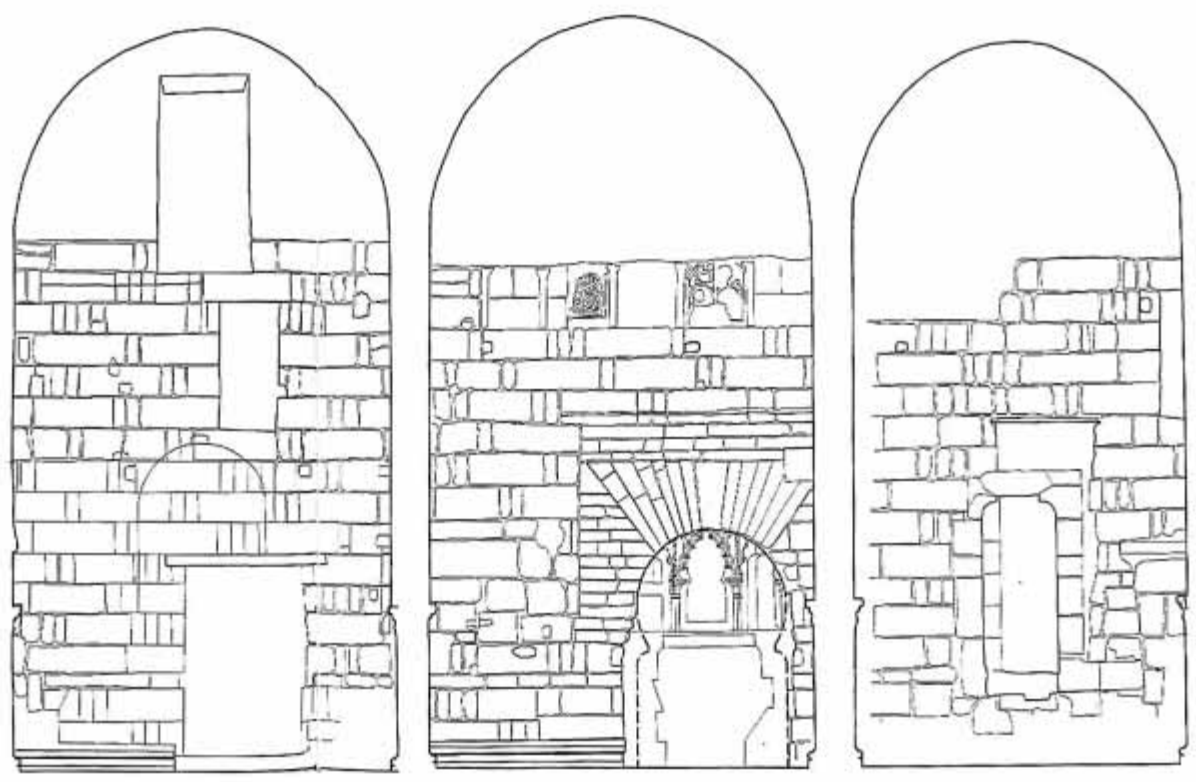

C

Fig. 9. Algunos ejemplos de construcciones en sillería de época califal. A: Detalle del puente de Guadalajara sobre el Henares (según Torres Balbas). B: Madinat al-Zahra; nicho de los baños de la terraza del Salón Rico (según Pavón Maldonado). C: Alzado del muro de la quibla de la Aljama de Almería -lglesia de San Juan(según: CSIC, EEA, A. Almagro) 


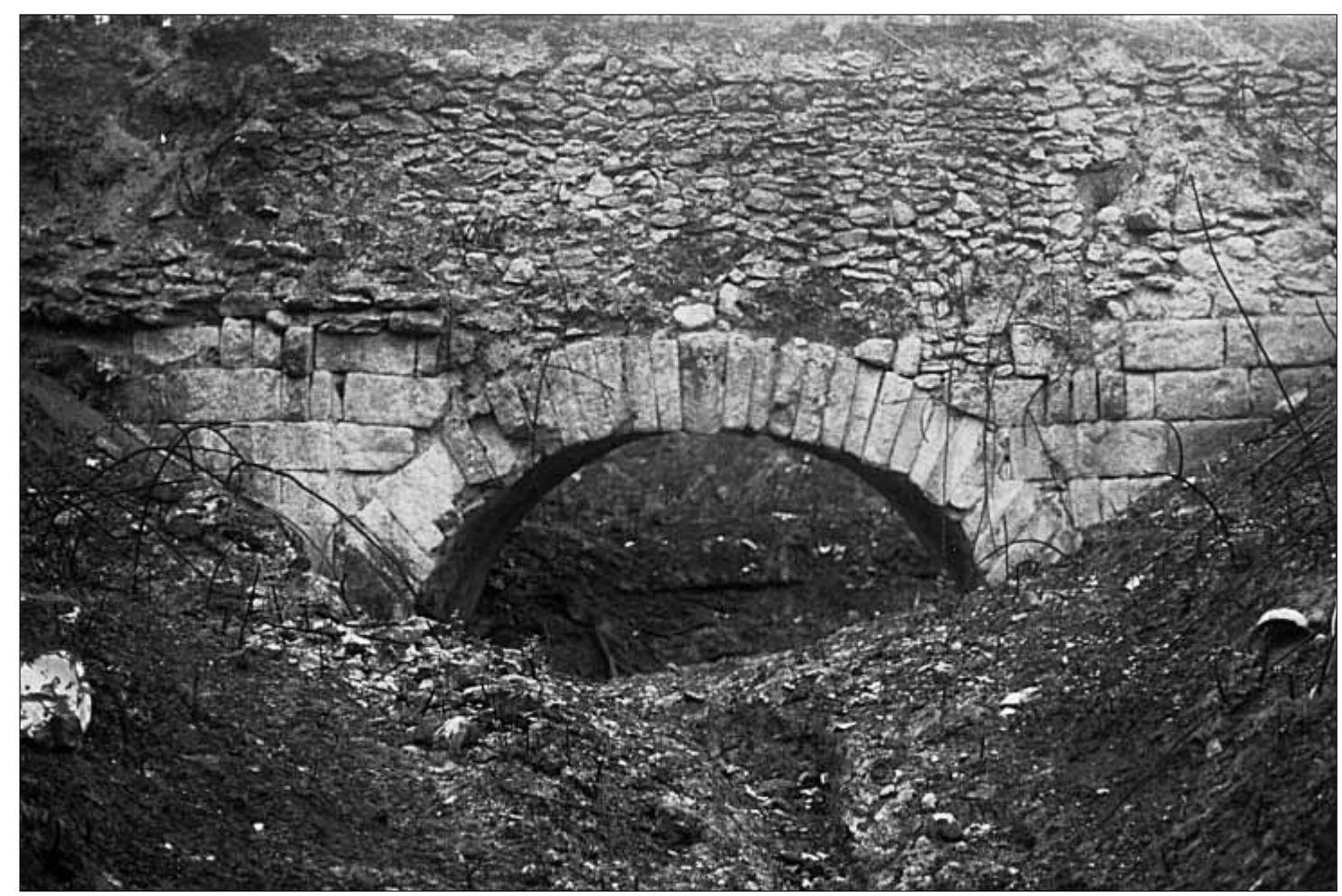

Lam. I. Puente sobre el barranco de la Frontera. Vista después del incendio forestal de 1994

Lam. 2. Puente sobre el barranco de la Frontera. Detalle del estribo norte

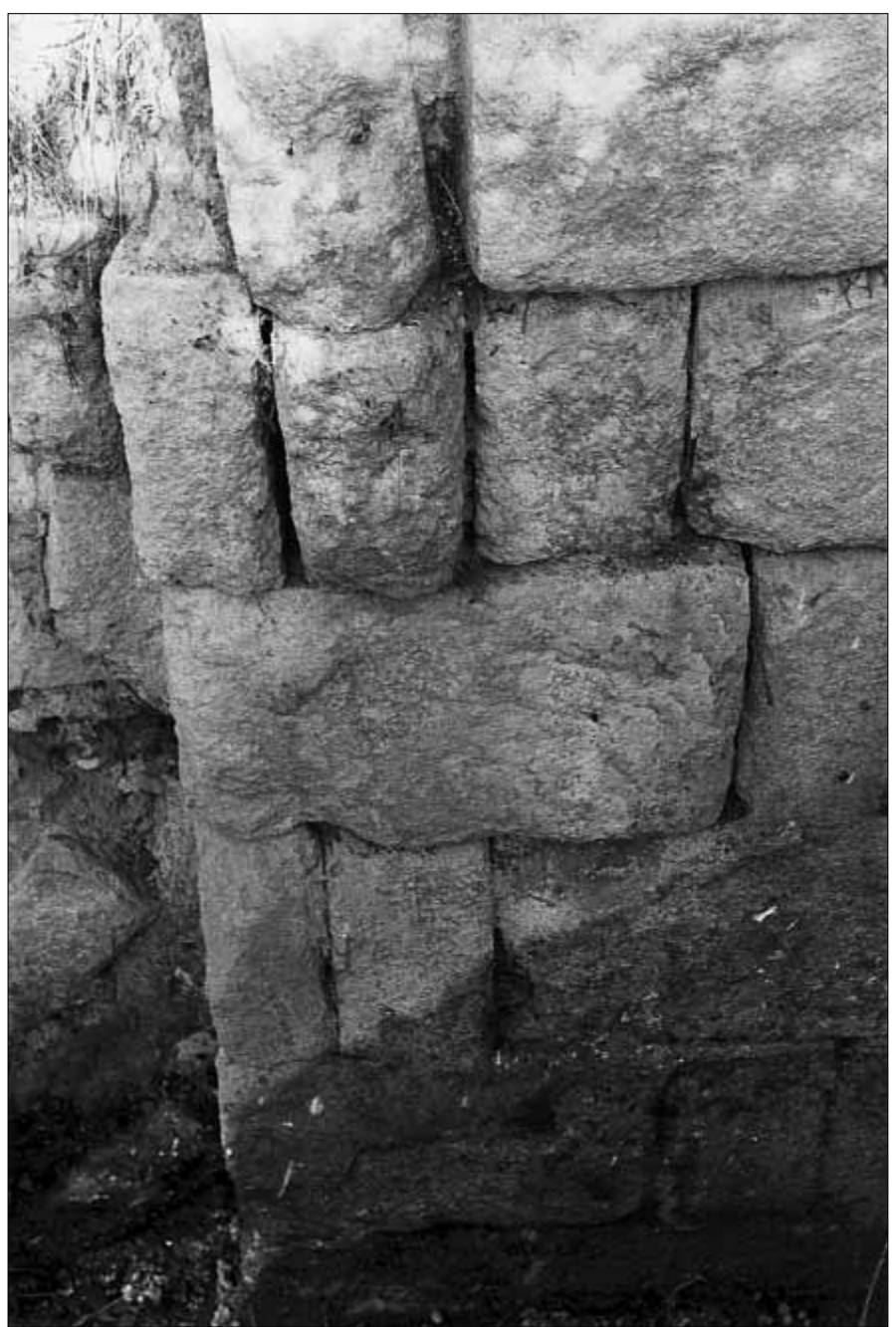




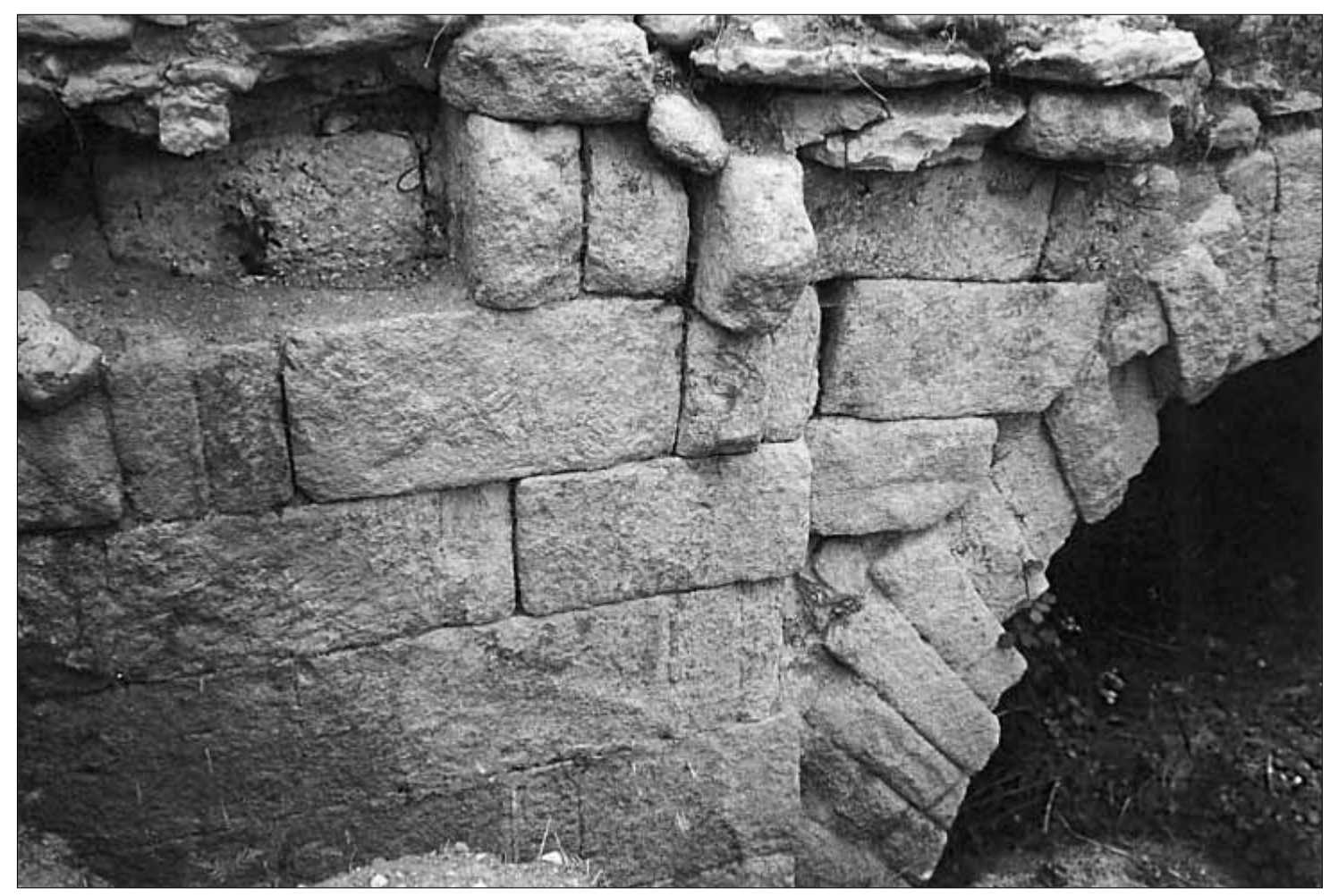

Lam. 3. Puente sobre el barranco de la Frontera. Estribo sur

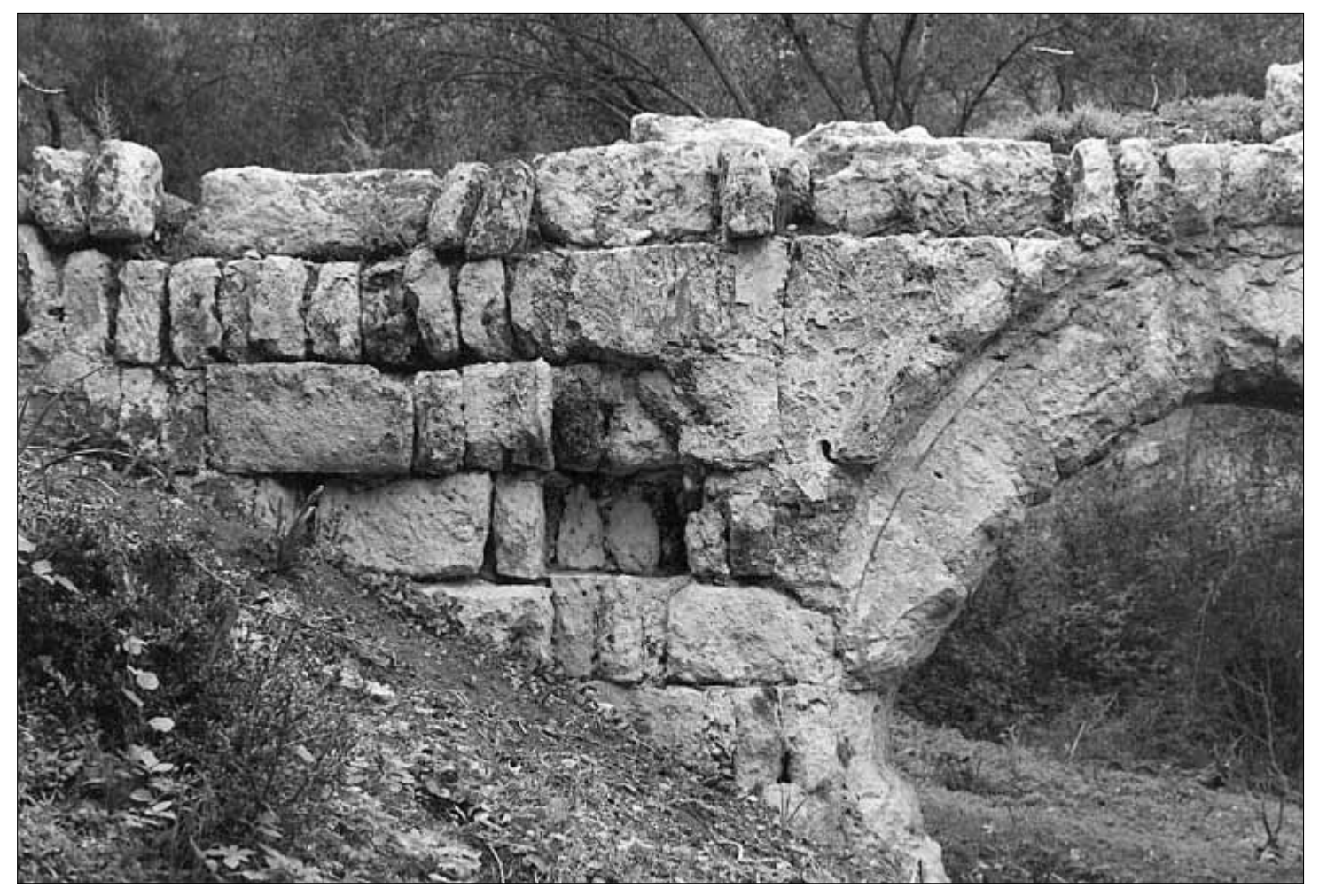

Lam. 4. Puente-Acueducto de Valdepuentes; Medina Azahara; Córdoba. Estribo oeste 


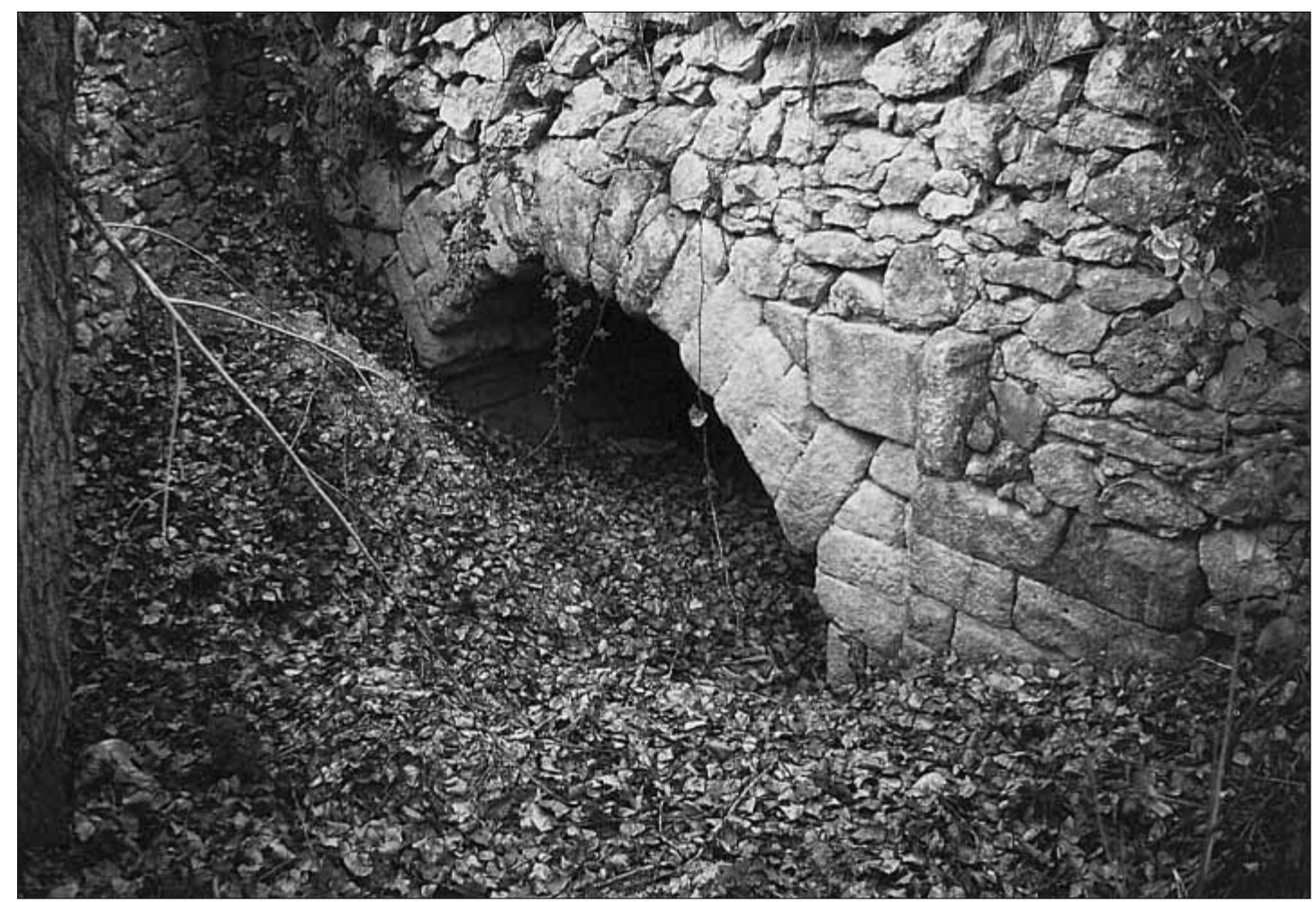

Lam. 5. Puente sobre el barranco de Perinos. Frente sur

Lam. 6. Puente sobre el barranco

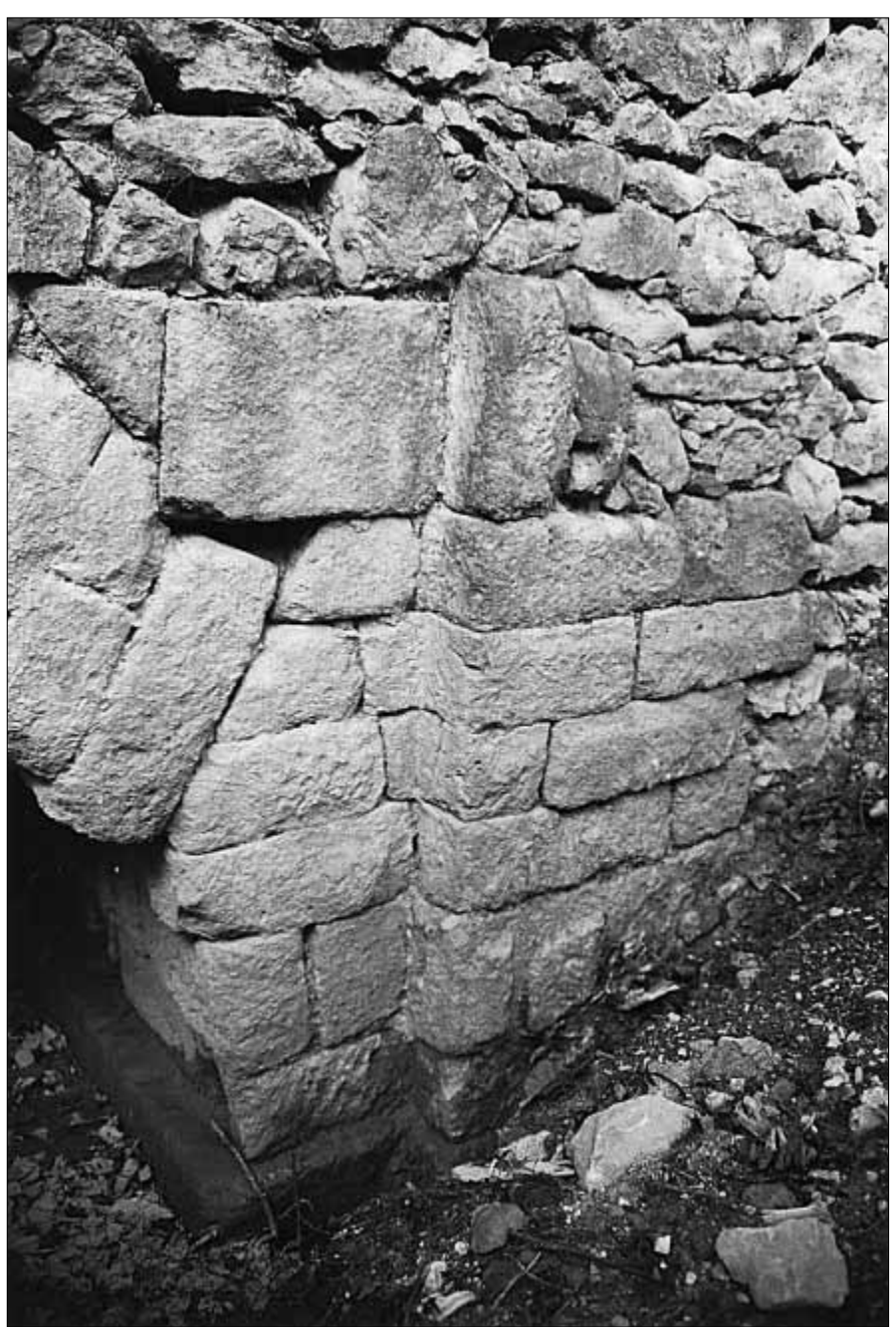
de Perinos. Estribo este 


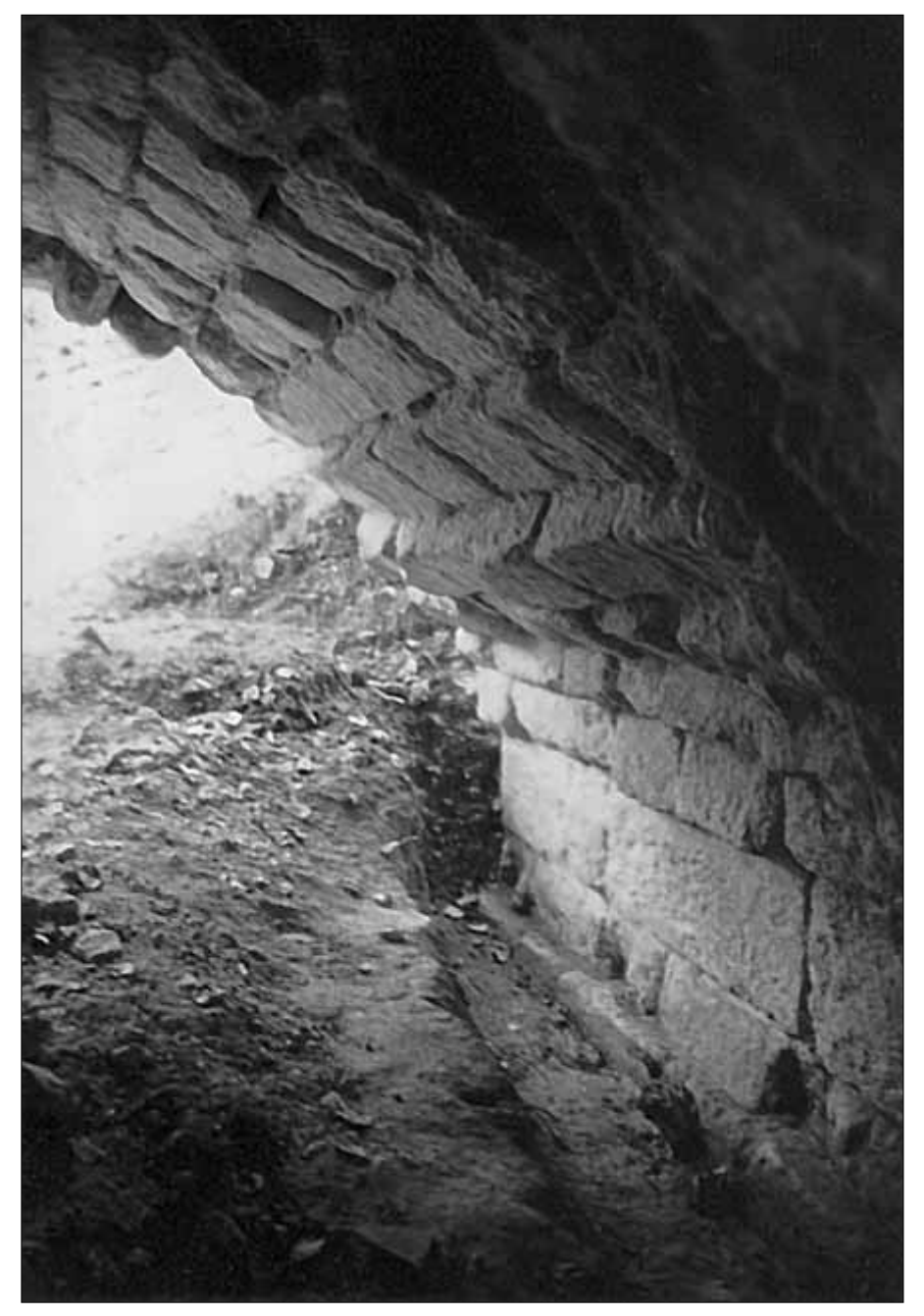

Lam. 7. Puente sobre el baranco

de Perinos. Vista parcial del intradós

Lam. 8. Puente sobre el barranco del Canyaret. Frente norte

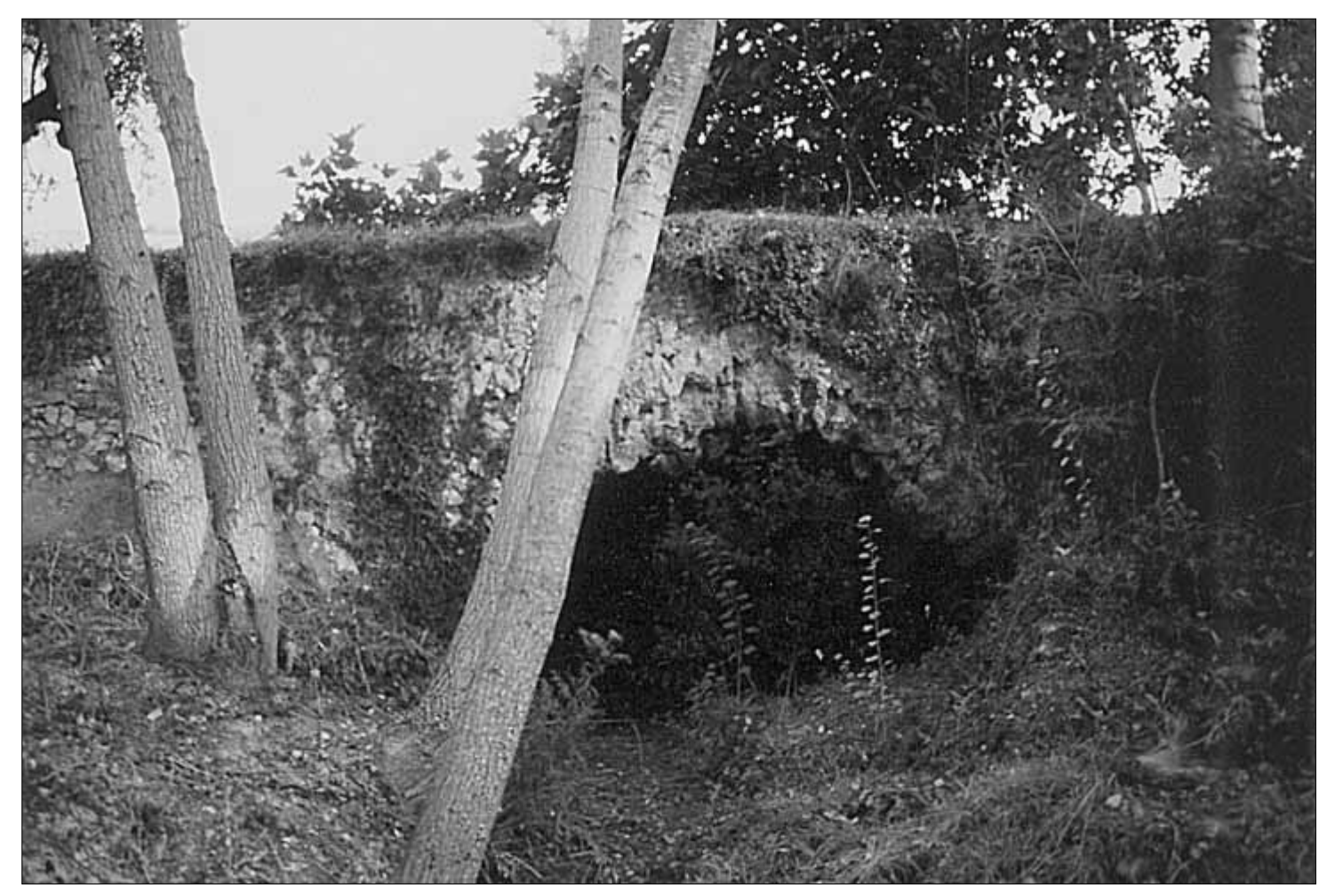




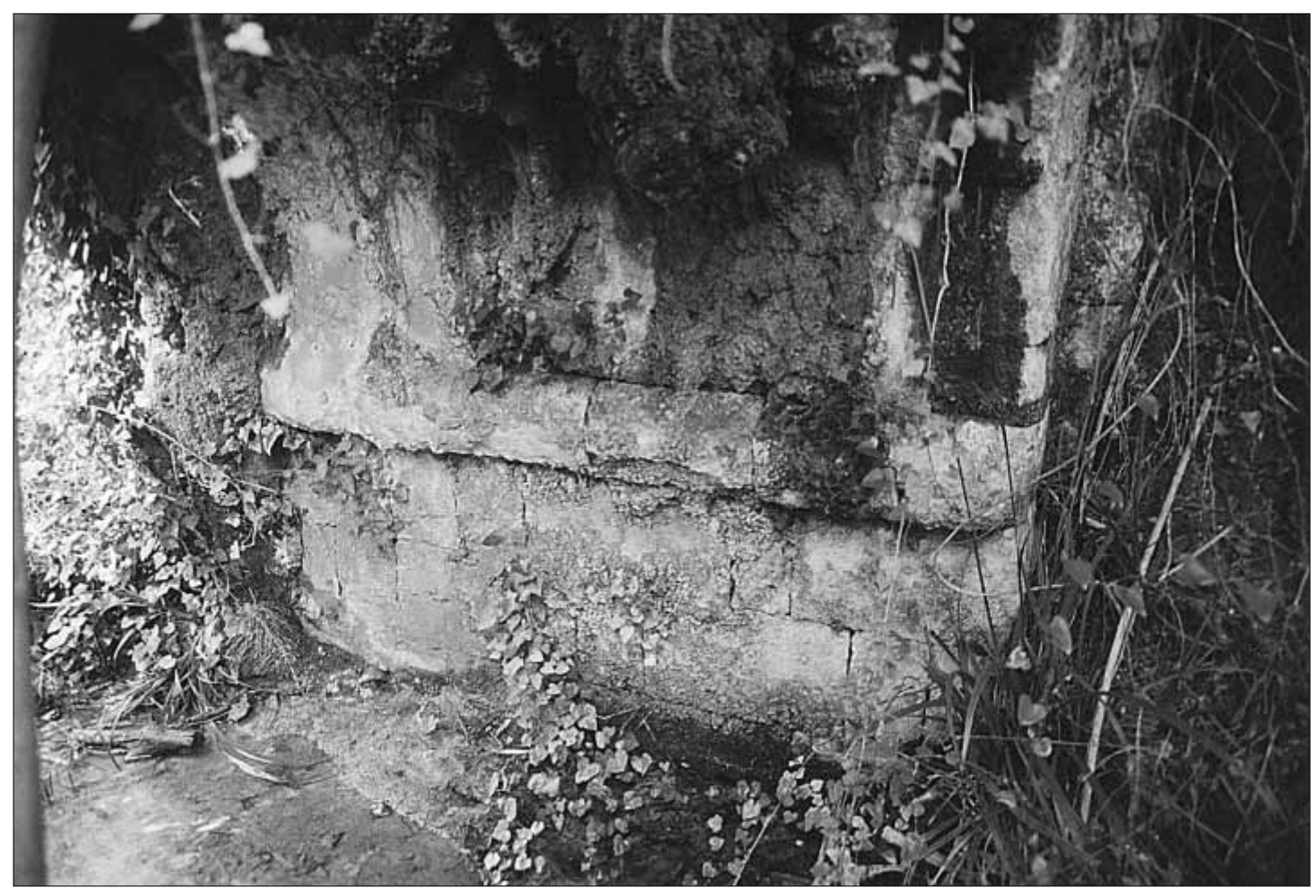

Lam. 9. Puente sobre el barranco del Canyaret. Estribo e imposta del costado este

Lam. 10. Puente sobre el barranco del Canyaret. Costado este

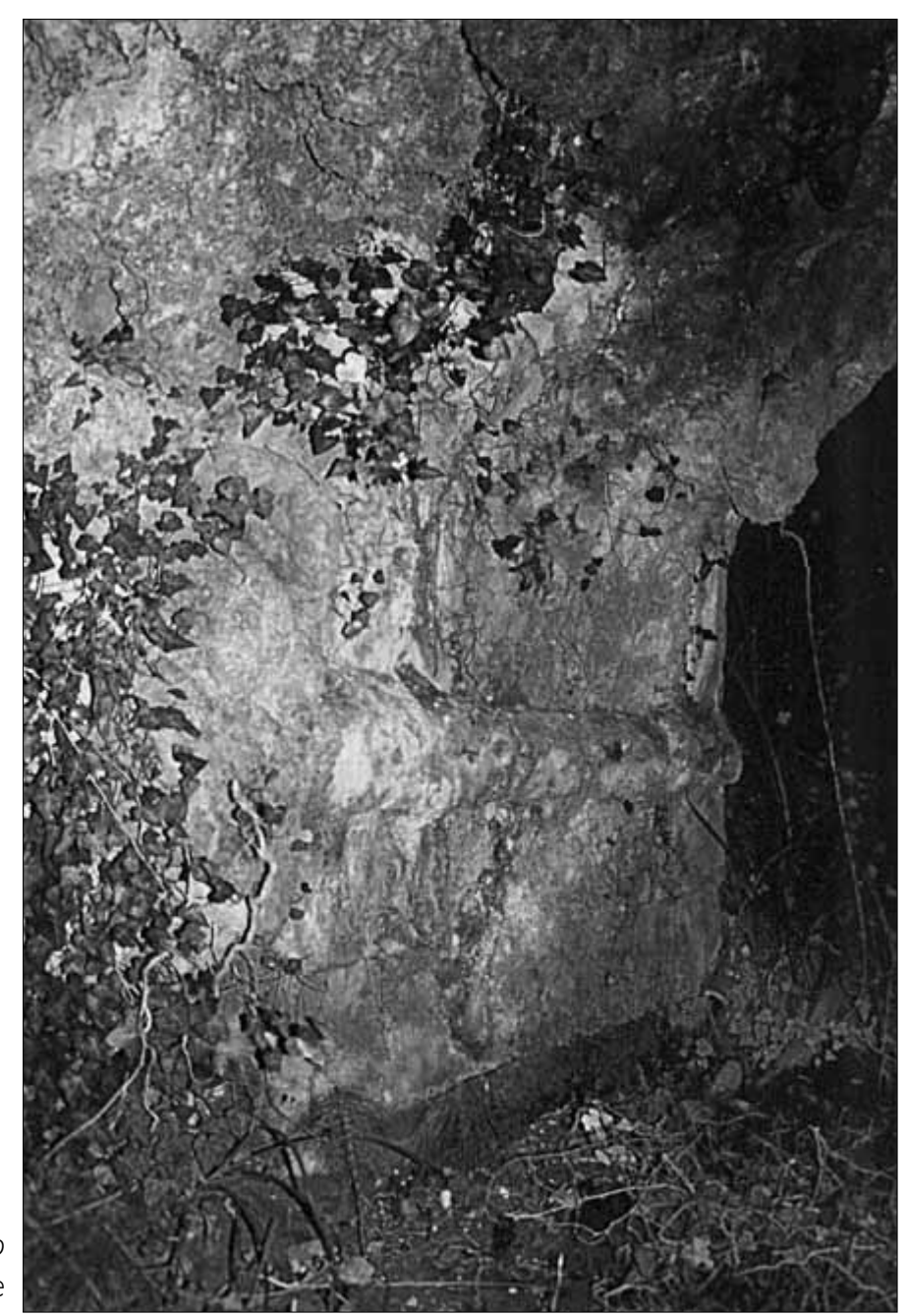




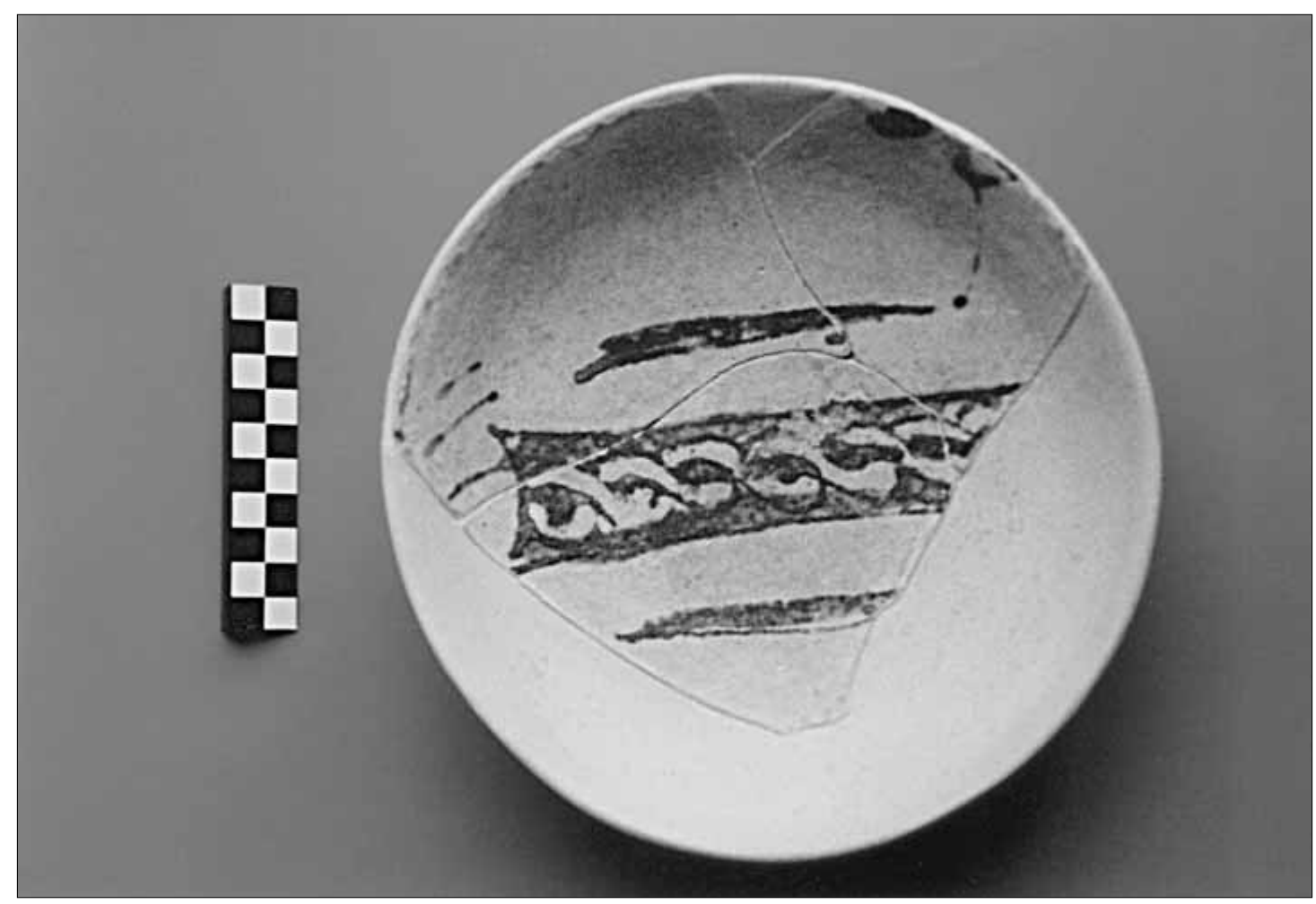

Lam. I I. Ataifor en verde y manganeso de els Vilars 